\title{
An integrated shear-wave velocity model for the Groningen gas field, The Netherlands
}

\author{
Pauline P. Kruiver ${ }^{1}$ (D) Ewoud van Dedem ${ }^{2}$ - Remco Romijn ${ }^{3}$. \\ Ger de Lange ${ }^{1} \cdot$ Mandy Korff $^{1,4} \cdot$ Jan Stafleu $^{5}$ • \\ Jan L. Gunnink ${ }^{5}$ - Adrian Rodriguez-Marek ${ }^{6}$. \\ Julian J. Bommer ${ }^{7} \cdot$ Jan van Elk $^{3} \cdot$ Dirk Doornhof $^{3}$
}

Received: 12 May 2016/ Accepted: 8 February 2017/Published online: 20 February 2017

(C) The Author(s) 2017. This article is published with open access at Springerlink.com

\begin{abstract}
A regional shear-wave velocity $\left(V_{S}\right)$ model has been developed for the Groningen gas field in the Netherlands as the basis for seismic microzonation of an area of more than $1000 \mathrm{~km}^{2}$. The $\mathrm{V}_{\mathrm{S}}$ model, extending to a depth of almost $1 \mathrm{~km}$, is an essential input to the modelling of hazard and risk due to induced earthquakes in the region. The detailed $V_{S}$ profiles are constructed from a novel combination of three data sets covering different, partially overlapping depth ranges. The uppermost $50 \mathrm{~m}$ of the $\mathrm{V}_{\mathrm{S}}$ profiles are obtained from a high-resolution geological model with representative $V_{S}$ values assigned to the sediments. Field measurements of $V_{S}$ were used to derive representative $V_{S}$ values for the different types of sediments. The profiles from 50 to $120 \mathrm{~m}$ are obtained from inversion of surface waves recorded (as noise) during deep seismic reflection profiling of the gas reservoir. The deepest part of the profiles is obtained from sonic logging and $V_{P}-V_{S}$ relationships based on measurements in deep boreholes. Criteria were established for the splicing of the three portions to generate continuous models over the entire depth range for use in site response calculations, for which an elastic half-space is assumed to exist below a
\end{abstract}

Electronic supplementary material The online version of this article (doi:10.1007/s10518-017-0105-y) contains supplementary material, which is available to authorized users.

Pauline P. Kruiver

Pauline.kruiver@deltares.nl

1 Deltares, P.O. Box 177, 2600 MH Delft, The Netherlands

2 Shell Global Solutions International BV, P.O. Box 60, 2280 AB Rijswijk, The Netherlands

3 Nederlandse Aardolie Maatschappij B.V., Schepersmaat 2, 9405 TA Assen, The Netherlands

4 Department Geoscience and Engineering, Delft University of Technology, Stevinweg 1, $2628 \mathrm{CN}$ Delft, The Netherlands

5 TNO Geological Survey of the Netherlands, Princetonlaan 6, 3584 CB Utrecht, The Netherlands

6 Charles E Via Jr. Dept. Civil \& Environmental Engineering, Virginia Tech, Blacksburg, VA 24061, USA

7 Department of Civil and Environmental Engineering, Imperial College London, London SW7 2AZ, UK 
clear stratigraphic boundary and impedance contrast encountered at about $800 \mathrm{~m}$ depth. In order to facilitate fully probabilistic site response analyses, a scheme for the randomisation of the $\mathrm{V}_{\mathrm{S}}$ profiles is implemented.

Keywords Shear-wave velocity - Site response analysis - Geology · Randomisation · Surface-wave inversion · Microzonation

\section{Introduction}

The province of Groningen in the Netherlands (Fig. 1) is experiencing induced earthquakes due to the exploitation of a large onshore gas field. The largest induced earthquake to date was the Huizinge event of August 2012 with a local magnitude $\mathrm{M}_{\mathrm{L}}$ of 3.6 (moment magnitude $\mathbf{M}=3.4$ ). This earthquake initiated the development of a comprehensive probabilistic seismic hazard and risk model for the region (Bourne et al. 2015), covering an area of about $35 \times 45 \mathrm{~km}$.

Rather than using proxy parameters such as the time-averaged $30 \mathrm{~m}$ shear-wave velocity, $\mathrm{V}_{\mathrm{S} 30}$, to capture site effects, the aim has been to more faithfully model the dynamic effects of the specific profiles in the field, which are overlain by a particularly thick deposit of soft soils. To this end, a seismic microzonation of the field has been developed, the starting point of which is the model of shear-wave velocity $\left(\mathrm{V}_{\mathrm{S}}\right)$ profiles described herein. The field-wide $\mathrm{V}_{\mathrm{S}}$ profiles are subsequently used to define a reference rock horizon —at a depth of about $800 \mathrm{~m}$ - and then used in a large number of site response analyses to obtain nonlinear frequency-dependent amplification factors, as described in Rodriguez-Marek et al. (2017). The final microzonation defines 161 zones. Bommer et al. (2017) explain the derivation of ground-motion prediction equations (GMPEs) for

Fig. 1 Location of the Groningen gas field (in red) in the northern part of the Netherlands

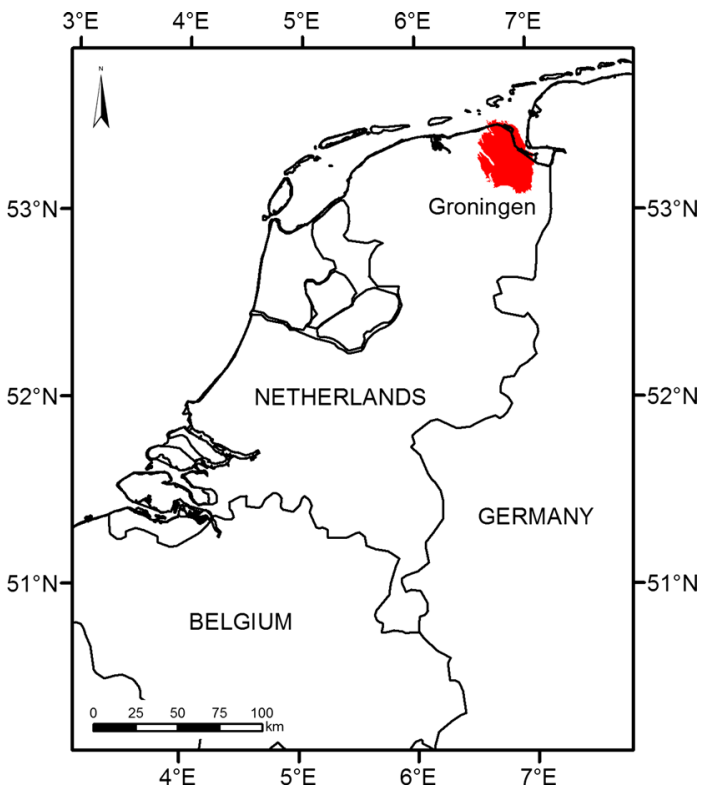


accelerations at the deep rock horizon and the process for combining the predicted rock motions with the nonlinear site amplification factors.

The work presented herein adds to the body of shared knowledge and experience of seismic microzonation in Europe, which includes, among many others, the EUROSEISTEST project in Volvi, Greece (Pitilakis et al. 1999), the characterisation of the Grenoble basin in France (Guéguen et al. 2007) and the microzonation of the city of Basel in Switzerland (Havenith et al. 2007). Each of these projects has made use of different types of data and measurements. The Groningen microzonation project marks an important contribution to the field since it uses innovative approaches. The project is also of broad interest since it applies to a much larger area than has been the focus for previous seismic microzonation projects. Another factor that makes the project relevant is that it corresponds to a region that is effectively aseismic in terms of tectonic earthquakes-the motivation for development of the Groningen microzonation is entirely due to induced seismicity.

This paper describes the development of the $V_{S}$ model for the Groningen field. The $V_{S}$ profiles have been constructed using a unique combination of $\mathrm{V}_{\mathrm{S}}$ models over three separate depth ranges that collectively cover the full range down to about $800 \mathrm{~m}$. The shallowest depth range, to $50 \mathrm{~m}$ below Dutch Ordnance Datum (NAP, which is approximately Mean Sea Level), is based on the high resolution 3D geological model GeoTOP (Stafleu et al. 2011; Stafleu and Dubelaar 2016), combined with representative $\mathrm{V}_{\mathrm{S}}$ distributions with depth for the sediments. The $\mathrm{V}_{\mathrm{S}}$ model for the intermediate depth range, from NAP$50 \mathrm{~m}$ to $\sim \mathrm{NAP}-120 \mathrm{~m}$, comes from the inversion of Rayleigh waves data (surface waves) using the Modal Elastic Inversion method (Ernst 2013) on the extensive reflection seismic survey data. The $\mathrm{V}_{\mathrm{S}}$ model for the third depth range, starting at $\sim \mathrm{NAP}-70 \mathrm{~m}$ to about NAP-800 $\mathrm{m}$ is based on the PreStack Depth Migration (PSDM) velocity model derived from sonic logs that is used to image the reservoir. These three models, all with different spatial resolutions, are spliced to obtain one $\mathrm{V}_{\mathrm{S}}$ model over the full depth range.

In order to obtain fully probabilistic estimates of the ground shaking hazard at the surface, the site amplification characteristics are modelled in a probabilistic framework (Bazzurro and Cornell 2004a, b). Therefore, $V_{S}$ profiles were constructed by sampling from statistical distributions of $V_{S}$ that were obtained from site-specific field measurements. The resulting randomized $V_{S}$ profiles capture the variability and uncertainty in the amplification factors. The randomisation scheme for $\mathrm{V}_{\mathrm{S}}$ includes confining stress dependent relations and correlations within and between units in the profile.

This paper first gives a short description of the geological setting. This is followed by a detailed description of the three different $\mathrm{V}_{\mathrm{S}}$ models. The subsequent sections elaborate on the construction of $V_{S}$ profiles, including splicing of the three $V_{S}$ models, layering and randomisation. Thereafter, the zonation of the field necessary for the aggregation of the probabilistic amplification factors is described. For illustration, the shallow $\mathrm{V}_{\mathrm{S}}$ model is used to construct a $V_{\mathrm{S} 30}$ map. The paper concludes with a discussion of potential improvements to the $\mathrm{V}_{\mathrm{S}}$ model that may be addressed in future work.

\section{Geological setting}

The area of Groningen consists of a mainly flat, low-lying area with an average surface level close to mean sea level. The geological history of the region includes the deposition of fluvial braid plain sands, ice sheet loading, erosion during Pleistocene ice ages, and an 
infill of Holocene shallow marine (intertidal) and terrestrial deposits consisting of soft clays, sands and the formation of peat. As a result, a thick layer of unconsolidated deposits (over $800 \mathrm{~m}$ thick) with a large degree of heterogeneity is present over the entire Groningen region. The Cretaceous limestones of the Chalk Group were selected as the reference horizon for site response analyses (Rodriguez-Marek et al. 2017). Hence the formations considered for the site response analysis are the Paleogene, Neogene and younger deposits overlying the Chalk Group (de Mulder et al. 2003; Vos 2015). The lowermost deposits are the Lower North Sea Group, which consists of an alternation of primarily marine grey sands and sandstones and clays of Late Paleocene to Middle Eocene age. On average, the base of the Lower North Sea Group is situated at a depth of $840 \mathrm{~m}$. The predominantly clayey marine formations of the Oligocene (Middle North Sea Group) are found between about 450 and $350 \mathrm{~m}$ depth, corresponding to the base of the overlying marine deposits of the Breda Formation (Miocene). This also corresponds to the base of the Upper North Sea Group. The Breda Formation consists of open marine clays, sandy clays and loam. The overlying sediments belong to the Oosterhout Formation (Pliocene), consisting of marine delta slope deposits of clay, fine sand and loam. The combination of the Lower, Middle and Upper North Sea Group is also known as the North Sea Supergroup (https://www.dinoloket.nl/en/nomenclature-deep). Stratigraphically, the overlying Pleistocene and Holocene formations belong to the North Sea Supergroup. The deposits of these formations are described separately below, owing to their heterogeneity, which is reflected in the variation in their geomechanical properties.

The uppermost deposits of Pleistocene and Holocene age are influenced by the last three ice ages and associated sea level fluctuations. During the Pleistocene, the sedimentary sequence is characterized by a succession of fluvial (Peize Formation, Appelscha Formation and Urk Formation), glacial (Peelo and Drente Formation) and marine deposits (Eem Formation) following the penultimate glacial stage. The Elsterian glaciation produced deep subglacial features ('tunnel valleys'), which were filled with sands and clays of the Peelo Formation and were buried by younger sediments. The second glaciation, the Drente Substage of the Saalian glacial, produced the till sheet that constitutes the Drente plateau. The ridge-and-valley topography is still present in the landscape stretching from the city of Groningen towards the South-East (Hondsrug). The region was not covered by ice-sheets during the last ice-age (Weichselian). During this period, a widespread superficial blanket of eolian sand formed that in many places marks the top of the Pleistocene deposits (the so-called cover sands). The northern part of the Netherlands borders the North Sea. During interglacial periods, a large part of Groningen became a coastal plain. The Holocene succession consists of alternations of shallow marine intertidal deposits (Naaldwijk Formation) and peat (Nieuwkoop Formation). Two distinct peat layers can be recognized: Basal peat and Holland peat. The Holocene succession reaches several tens of metres in the north (maximum thickness of $28 \mathrm{~m}$ in the far north) and is absent in the south of the region. A representative geological cross section of the top $25 \mathrm{~m}$ is shown in Fig. 2. This section clearly shows that the subsurface displays a large degree of heterogeneity due to the channel sands and the clayey deposits in the intertidal basin. An effort was made to combine all available geological and geomechanical data into a stochastic model that captures the spatial variability of these deposits. This is because the vertical position, thickness, lateral extent of soft layers (i.e. clay and peat) and the impedance contrasts at layer boundaries are dominant factors in site amplification. 


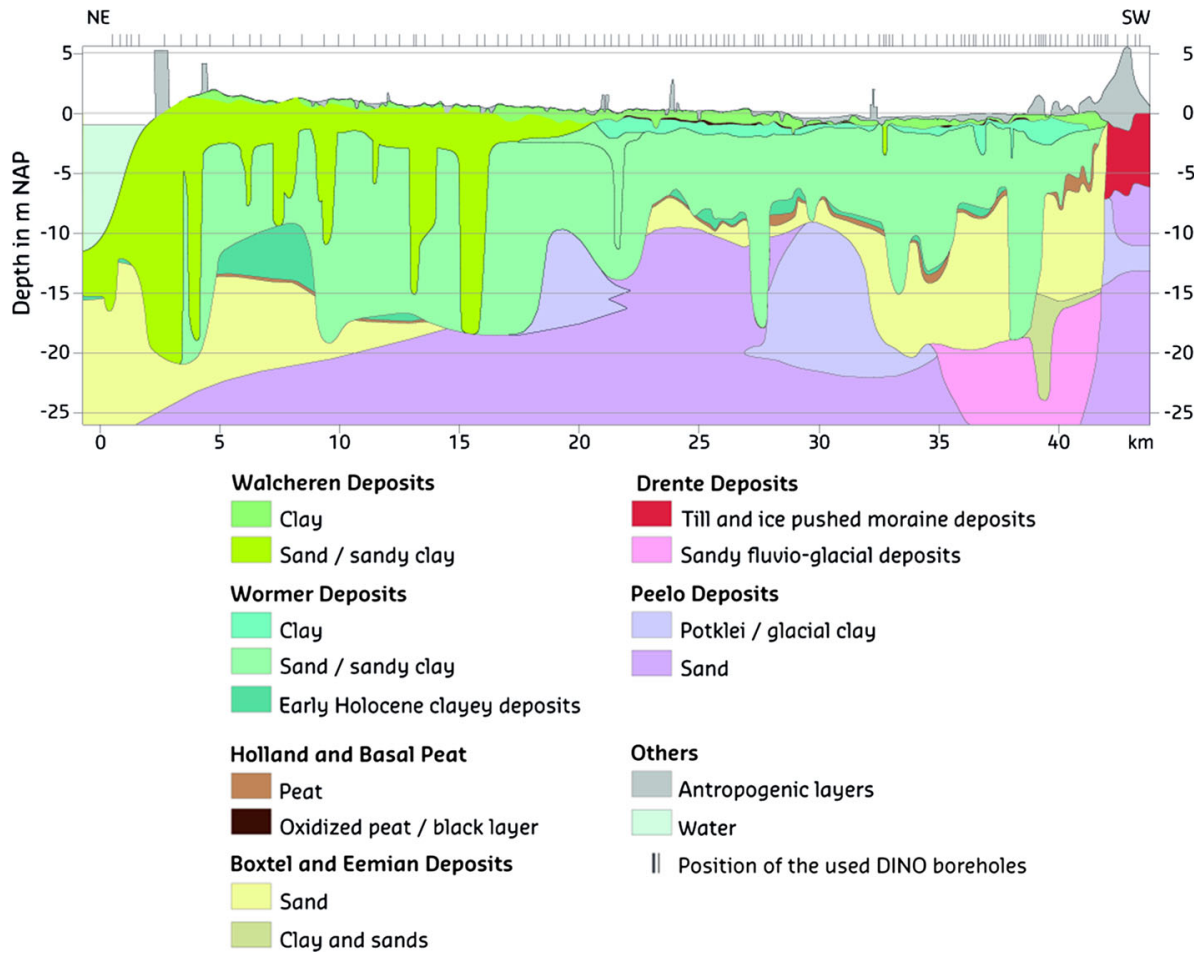

Fig. 2 Cross section of the top $25 \mathrm{~m}$ of Late Pleistocene and Holocene sediments from northeast (left) to southwest (right) (after Vos 2015). Walcheren and Wormer Deposits are members of the Naaldwijk Formation. The vertical scale is exaggerated

\section{Description of $V_{S}$ models}

The integrated model of $V_{S}$ from the surface to the base of the North Sea Supergroup is a combination of three different $\mathrm{V}_{\mathrm{S}}$ models, each with its own depth range. The top part of the model ranges from the surface to NAP-50 m and is constructed from the combination of the high resolution 3D geological voxel model GeoTOP constructed by TNO-Geological Survey of the Netherlands and Groningen specific $\mathrm{V}_{\mathrm{S}}$ data. The $\mathrm{V}_{\mathrm{S}}$ model for this depth range has been derived from seismic cone penetration tests (SCPT) that were linked to the geological units of the GeoTOP model. This $\mathrm{V}_{\mathrm{S}}$ model is referred to as the GeoTOP $\mathrm{V}_{\mathrm{S}}$ model.

The intermediate depth interval ranges from approximately NAP-40 m to NAP-120 m. Extensive reflection seismic surveys were conducted in the 1980s for imaging purposes of the reservoir. The legacy data were reprocessed using surface waves information to retrieve a $V_{S}$ model based on the Modal Elastic Inversion (MEI) method (Ernst 2013). This model is referred to as the MEI $\mathrm{V}_{\mathrm{S}}$ model.

The deepest depth interval ranges from approximately NAP-70 $\mathrm{m}$ to the base of the North Sea Supergroup, providing overlap with the MEI $V_{S}$ model. The $V_{S}$ model for this depth range is based on the pre-stack-depth-migration model (PSDM) of compressionwave velocity $\left(\mathrm{V}_{\mathrm{P}}\right)$ used to image the reservoir. The $\mathrm{V}_{\mathrm{P}}$ model is based on 70 sonic logs and well markers in 500 wells. The $V_{P}$ model is converted to a $V_{S}$ model using 
relationships for the $\mathrm{V}_{\mathrm{P}} / \mathrm{V}_{\mathrm{S}}$ ratio based on Groningen-specific data. This model is referred to as the Sonic $\mathrm{V}_{\mathrm{S}}$ model. The following sections describe each of these models in more detail.

\subsection{GeoTOP $V_{S}$ model}

GeoTOP describes the subsurface in voxels measuring 100 by 100 by $0.5 \mathrm{~m}(\mathrm{x}, \mathrm{y}, \mathrm{z})$ to a maximum depth of NAP-50 m. The model provides estimates of stratigraphy and lithology, including sand grain-size classes. The estimates are calculated using Sequential Gaussian Simulation (SGS) and Sequential Indicator Simulation (SIS) (Goovaerts 1997; Chilès and Delfiner 2012). These stochastic techniques allow the construction of multiple, equally probable 3D subsurface models as well as the evaluation of model uncertainty (Stafleu et al. 2011). The "most likely" subsurface model was determined from the multiple subsurface models, using the averaging technique described by Soares (1992). This "most likely" model is used in the construction of the GeoTOP $\mathrm{V}_{\mathrm{S}}$ model. The GeoTOP model (version 1.3) is publically available at https://www.dinoloket.nl/en/ subsurface-models (Stafleu and Dubelaar 2016).

The GeoTOP model of the north-eastern part of the Netherlands, including the Groningen region, was constructed using some 42,700 digital borehole descriptions from DINO, the national Dutch subsurface database operated by the Geological Survey. The largest part of these boreholes consists of manually-drilled auger holes collected by the Geological Survey during the 1:50,000 geological mapping campaigns. Most of the other borehole data comes from external parties such as groundwater companies and municipalities. Because of the large share of manually-drilled boreholes, borehole density decreases rapidly with depth.

An example of a cross section through the GeoTOP model is presented in Fig. 3, showing the stratigraphic units in the top panel and the lithological classes in the bottom panel. From top to bottom there are in this example Holocene Naaldwijk clays, the Holland and Basal Peat, sands of the Boxtel Formation and clays of the Peelo Formation.

The GeoTOP $V_{S}$ model associates each of the voxels of the GeoTOP model to a $V_{S}$ value. The various constituents of the Groningen subsoil have different geological histories, as described above, and consequently have different geomechanical characteristics. A Holocene clay will have a different $V_{S}$ than a Pleistocene clay that has experienced loading by ice sheets. Therefore, different $\mathrm{V}_{\mathrm{S}}$ statistical distributions were derived for each of the stratigraphic and lithological combinations that are found in the Groningen field. In the following, the combination of stratigraphy and lithology is referred to as "unit".

A data set of 88 SCPTs in Groningen provided the input for these statistical distributions. The $\mathrm{V}_{\mathrm{S}}$ measurements from the SCPTs at each depth were associated with a stratigraphy, inferred from GeoTOP, and lithological class, inferred from cone resistance and friction ratio of the accompanying cone penetration test (CPT). The effective isotropic confining stress, $\sigma_{o}^{\prime}$ (i.e., the average of the vertical and two horizontal components of the effective stress) for each depth is computed using the unit weight of the overlying sediments and assuming a mean water table of $1 \mathrm{~m}$ below the surface. For brevity, the effective isotropic confining stress is hereafter simply referred to as "confining stress". Next, $\mathrm{V}_{\mathrm{S}}$ values from the SCPTs were clustered for each unit and $\ln V s$ was plotted versus the natural logarithm of the confining stress. The clustered $V_{S}$ values were then used to develop models to assign $V_{S}$ values to each of the GeoTOP voxel-stacks. A voxel-stack is a vertical sequence of voxels at a particular (x,y)-location in the GeoTOP grid. This approach 

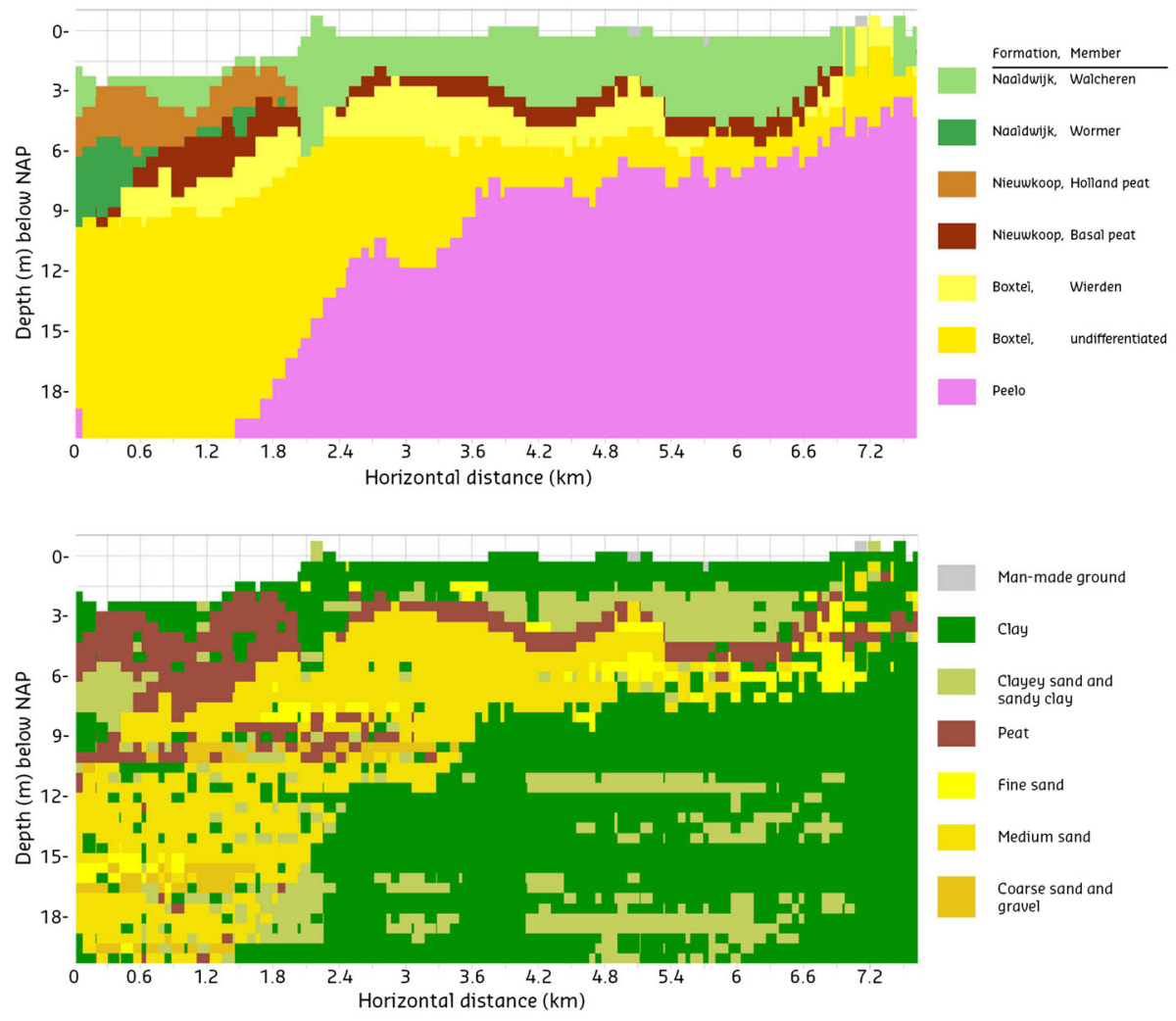

Fig. 3 Cross section through a small part of the GeoTOP model, showing the stratigraphic units (top) and lithological class (bottom)

enhances the inclusion of geological information in the $V_{S}$ profiles generated for this depth range.

Generally, $V_{S}$ increases with confining stress (e.g. Hardin 1978; Jamiolkowski et al. 1991; Yamada et al. 2008). Therefore, we checked for confining stress dependence within each group of $V_{S}$ data. A typical model for $V_{S}$ dependence on confining stress is:

$$
\ln V s=\ln V s_{1}+n \ln \left(\frac{\sigma_{o}^{\prime}}{p_{a}}\right)
$$

where $\sigma_{o}^{\prime}$ is the confining stress, $p_{a}$ is atmospheric pressure, $\ln V s_{1}$ is a parameter that represents the shear-wave velocity at a confining stress equal to one atmosphere, and $n$ is the slope that defines confining stress dependence (Sykora 1987). The parameters $n$ and $\ln V s_{1}$ and their statistics were determined for each unit. Shear-wave velocity values are assumed to be log-normally distributed; hence the ln-mean and the standard deviation fully define the distribution. The development of the confining stress-dependent $V_{S}$ models considered three different cases. The first case is when the confining stress-dependence is fully defined by the SCPT data. A second case is for units that do not show confining stress dependence. The last case is for units where the data is insufficient to define the confining stress-dependence, but such dependence is to be expected based on analogy to similar 
sediments elsewhere in the field. For these units, the parameters of Eq. 1 are based on existing literature and expert judgment.

Two examples of $V_{S}$ data for typical units with numerous observations are shown in Fig. 4. The mean $V_{S}$ at a certain confining stress is described by the slope $n$ and the intercept $\ln V_{S I}$, while the standard deviation depends on the number of observations, mean $\ln \left(\sigma_{0}^{\prime} / p_{a}\right)$, the sum of squares of $\ln \left(\sigma_{0}^{\prime} / p_{a}\right)$ and the total variance of $\mathrm{V}_{\mathrm{S}}$ (Montgomery et al. 2011). As indicated previously, the $V_{S}$ profiles also need to be randomised (described in Sect. 4.1), for which the above described mean $V_{S}$ and standard deviation will be used. There were sufficient observations (a minimum of 20) for 10 units to derive a confining stress-dependent relation based on SCPT data. The parameters describing the confining stress dependence defined by the SCPT data are given in Table 1 . The values of the slope $n$ for Groningen clay (including sandy clay and clayey sand) range from 0.18 to 0.43 with an average of 0.28 . This compares well with literature values for clay, which are generally given as $n=0.25$ (Hardin 1978; Jamiolkowski et al. 1991; Yamada et al. 2008). The slope $n$ depends on the type of sediment (Fig. 4): clays of the Peelo Formation (Pleistocene glacial deposits) have a stronger confining stress dependence (larger $n$ ) than clays of the Naaldwijk Formation (Holocene tidal deposits) which is generally present at much shallower depths and thus lower confining stresses.

For several units, confining stress dependence is not apparent in the SCPT data, showing an $n$ close to 0 or even slightly negative. Figure 5 shows $\mathrm{V}_{\mathrm{S}}$ data for medium sand from the Boxtel Formation. Since the slope in this case is very close to $0(0.07)$, no confining stress dependence was imposed for this unit. In some other cases, the geological history implies that confining stress dependence is not expected. For example, the clay from the Drente Formation formed under varying glacial conditions and the effect of spatially varying loading is much larger than the confining stress dependence. The distributions of these constant $\mathrm{V}_{\mathrm{S}}$ units are defined by the mean and standard deviations of $\ln V s$. These are summarised in Table 2. A minimum standard deviation of 0.2 is imposed. This lower limit was used in the past as measurement uncertainty in $V_{S}$ profiles (Coppersmith et al. 2014). A standard deviation 0.27 is imposed on all peats, based on the observations from the SCPT data set for Nieuwkoop Holland Peat.

The last class of $\mathrm{V}_{\mathrm{S}}$ consists of units for which confining stress dependence of $\mathrm{V}_{\mathrm{S}}$ is to be expected, but there are not enough data in the SCPT data set to constrain this
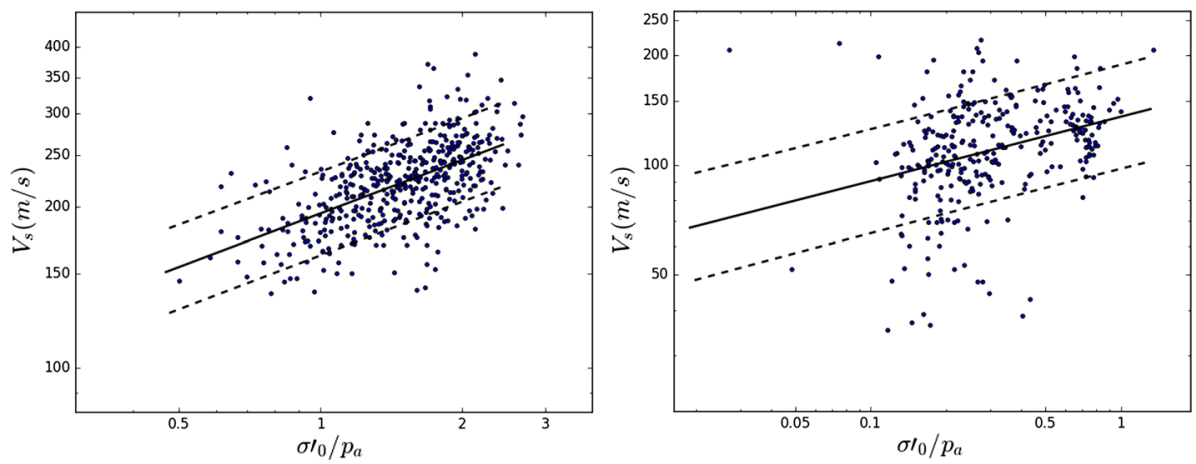

Fig. 4 Example of numerous $V_{S}$ observations in the SCPT data set, for clays from the Peelo Formation (left) and Naaldwijk Formation (right). The solid line describes the regression while dotted lines indicate $95 \%$ confidence intervals 
Table 1 Look-up table summarising parameters for the confining stress dependent $\mathrm{V}_{\mathrm{S}}$ (Eq. 1) from SCPTs

\begin{tabular}{|c|c|c|c|c|c|c|c|}
\hline Formation & Lithological class & $\begin{array}{l}\text { \# } \\
\text { Obs. }\end{array}$ & $\begin{array}{l}\text { Slope } \\
n\end{array}$ & $\begin{array}{l}\text { Intercept } \\
\mathrm{V}_{\mathrm{S} 1}(\mathrm{~m} / \mathrm{s})\end{array}$ & $\begin{array}{l}\text { Mean } \\
\ln \left(\sigma_{0}^{\prime} / p_{a}\right)\end{array}$ & $\begin{array}{l}\text { Sum of } \\
\text { squares } \\
\ln \left(\sigma_{0}^{\prime} / p_{a}\right)\end{array}$ & $\begin{array}{l}\text { Total } \\
\text { variance of } \\
\ln \left(V_{S}\right)\end{array}$ \\
\hline Boxtel & $\begin{array}{l}\text { Sandy clay and } \\
\text { clayey sand }\end{array}$ & 43 & 0.20 & 217.0 & 0.10 & 5.67 & 0.039 \\
\hline Boxtel & Fine sand & 260 & 0.11 & 247.2 & -0.057 & 64.41 & 0.054 \\
\hline Naaldwijk & Clay & 303 & 0.18 & 135.6 & -1.20 & 107.49 & 0.11 \\
\hline Naaldwijk & $\begin{array}{l}\text { Sandy clay and } \\
\text { clayey sand }\end{array}$ & 245 & 0.28 & 190.6 & -0.98 & 59.65 & 0.066 \\
\hline Naaldwijk & Fine sand & 166 & 0.36 & 247.2 & -0.78 & 34.05 & 0.099 \\
\hline $\begin{array}{l}\text { Nieuwkoop } \\
\text { Basal Peat }\end{array}$ & Peat & 22 & 0.57 & 156.0 & -0.77 & 3.70 & 0.19 \\
\hline Peelo & Clay & 455 & 0.33 & 194.4 & 0.39 & 41.89 & 0.033 \\
\hline Peelo & $\begin{array}{l}\text { Sandy clay and } \\
\text { clayey sand }\end{array}$ & 41 & 0.43 & 181.3 & 0.66 & 2.59 & 0.033 \\
\hline Peelo & Fine sand & 222 & 0.10 & 265.1 & 0.54 & 16.26 & 0.022 \\
\hline Peelo & $\begin{array}{l}\text { Medium and coarse } \\
\text { sand, gravel and } \\
\text { shells }\end{array}$ & 72 & 0.24 & 265.1 & 0.61 & 3.04 & 0.020 \\
\hline
\end{tabular}

During random sampling, a minimum standard deviation of 0.2 is imposed

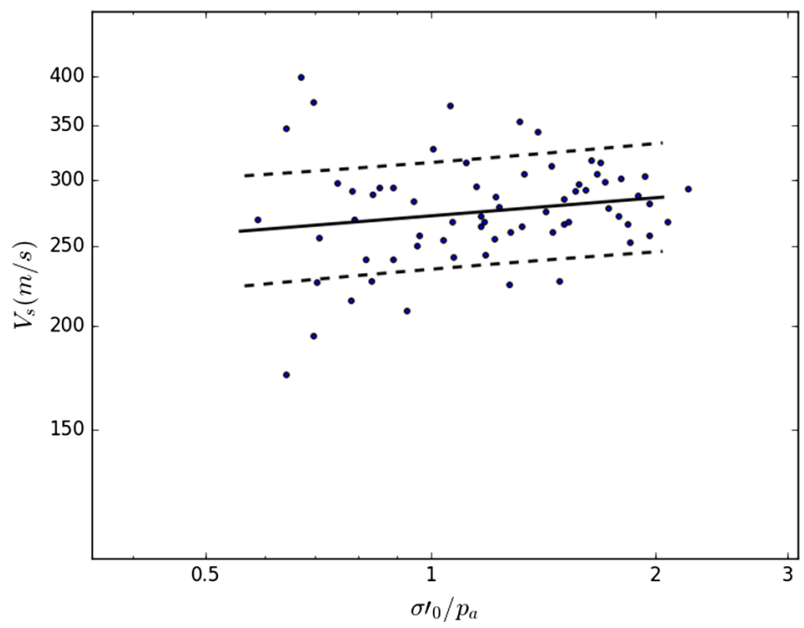

Fig. 5 Example of $\mathrm{V}_{\mathrm{S}}$ independent of confining stress, $n=0.07$ based on the data for medium sand of the Boxtel Formation. For this data set, a slope of $n=0$ is chosen. The solid line describes the regression while dotted lines indicate $95 \%$ confidence intervals

relationship. In that case, we estimate $n$ from literature. We use $n=0.25$ for clay, for all lithoclasses within Nieuwkoop Basal Peat and for peats within Pleistocene Formations following Hardin (1978), Jamiolkowski et al. (1991) and Yamada et al. (2008). For sand, we use measured coefficients of uniformity $\mathrm{C}_{\mathrm{u}}$ from Groningen to estimate $n$ using Menq (2003). This results in values for $n$ varying between 0.25 and 0.29 . In this case, no average 
Table 2 Look-up table summarising parameters for units with constant $\mathrm{V}_{\mathrm{S}}$

\begin{tabular}{|c|c|c|c|c|c|c|}
\hline Formation & Lithological class & $\begin{array}{l}\# \\
\text { Obs. }\end{array}$ & $\begin{array}{l}\text { Mean } \\
\mathrm{V}_{\mathrm{S}} \\
(\mathrm{m} / \mathrm{s})\end{array}$ & $\begin{array}{l}\text { Standard } \\
\text { deviation } \\
\ln \left(V_{S}\right)\end{array}$ & $\begin{array}{l}\text { Coefficient } \\
\text { of variance }\end{array}$ & Source \\
\hline $\begin{array}{l}\text { Anthropogenic } \\
\text { material }\end{array}$ & All & 87 & 167.3 & 0.43 & 0.084 & SCPT \\
\hline Appelscha & $\begin{array}{l}\text { Sandy clay and clayey } \\
\text { sand }\end{array}$ & 0 & 350.7 & 0.20 & 0.034 & Estimate \\
\hline Appelscha & Fine sand & 0 & 350.7 & 0.20 & 0.034 & Estimate \\
\hline Appelscha & Medium and coarse sand & 0 & 399.4 & 0.20 & 0.033 & Estimate \\
\hline Boxtel & Medium and coarse sand & 67 & 275.9 & 0.20 & 0.036 & SCPT \\
\hline Boxtel & Fine sand & 0 & 354.2 & 0.20 & 0.034 & $\begin{array}{c}\text { Wassing } \\
\text { et al. } \\
\text { (2003) }\end{array}$ \\
\hline Drachten & Medium and coarse sand & 0 & 450.3 & 0.20 & 0.033 & Estimate \\
\hline Drente & Peat & 0 & 228.1 & 0.27 & 0.050 & Estimate \\
\hline Drente & Clay & 0 & 200.3 & 0.20 & 0.038 & Estimate \\
\hline Drente & $\begin{array}{l}\text { Sandy clay and clayey } \\
\text { sand }\end{array}$ & 0 & 210.6 & 0.20 & 0.037 & Estimate \\
\hline $\begin{array}{l}\text { Drente, Gieten } \\
\text { member }\end{array}$ & Peat & 0 & 228.1 & 0.27 & 0.050 & Estimate \\
\hline $\begin{array}{l}\text { Drente, Gieten } \\
\text { member }\end{array}$ & Clay & 0 & 200.3 & 0.20 & 0.035 & Estimate \\
\hline $\begin{array}{l}\text { Drente, Gieten } \\
\text { member }\end{array}$ & $\begin{array}{l}\text { Sandy clay and clayey } \\
\text { sand }\end{array}$ & 33 & 210.6 & 0.20 & 0.037 & SCPT \\
\hline Eem & $\begin{array}{l}\text { Sandy clay and clayey } \\
\text { sand }\end{array}$ & 24 & 259.8 & 0.20 & 0.036 & SCPT \\
\hline Eem & Fine sand & 31 & 257.2 & 0.20 & 0.036 & SCPT \\
\hline Eem & Medium and coarse sand & 7 & 267.7 & 0.20 & 0.036 & SCPT \\
\hline $\begin{array}{l}\text { Nieuwkoop, } \\
\text { Holland Peat }\end{array}$ & Peat & 13 & 83.9 & 0.27 & 0.061 & SCPT \\
\hline $\begin{array}{l}\text { Nieuwkoop, } \\
\text { Holland Peat }\end{array}$ & Clay & 0 & 84.8 & 0.27 & 0.061 & Estimate \\
\hline $\begin{array}{l}\text { Nieuwkoop, } \\
\text { Holland Peat }\end{array}$ & $\begin{array}{l}\text { Sandy clay and clayey } \\
\text { sand }\end{array}$ & 0 & 109.9 & 0.27 & 0.057 & Estimate \\
\hline $\begin{array}{l}\text { Nieuwkoop, } \\
\text { Holland Peat }\end{array}$ & $\begin{array}{l}\text { Fine, medium and coarse } \\
\text { sand, gravel and shells }\end{array}$ & 0 & 138.4 & 0.27 & 0.055 & Estimate \\
\hline
\end{tabular}

$\mathrm{V}_{\mathrm{S}}$ estimates were available from the SCPT data set. Therefore, we used judgement to infer average $\mathrm{V}_{\mathrm{S}}$ for these units. Next, the intercept $\ln V s_{1}$ was determined such that the estimate of $\mathrm{V}_{\mathrm{S}}$ occurs at the average depth of occurrence in the region and consistent with the slope $n$. In the Groningen region, the intercept at $\ln \left(\frac{\sigma_{o}^{\prime}}{p_{a}}\right)=0$ corresponds to a depth of approximately 13 to $14 \mathrm{~m}$. The parameters describing the confining stress dependence in this fashion are given in Table 3. A standard deviation of 0.27 for $\ln V_{S}$ is imposed for all peats, and a value of 0.20 for all other lithologies, consistent with the values from Table 1 and Table 2. 
Table 3 Look-up table summarising parameters for the confining stress dependent $V_{S}$ (Eq. 1) from estimates

\begin{tabular}{lllll}
\hline Formation & Lithological class & $\begin{array}{l}\text { Slope } \\
n\end{array}$ & $\begin{array}{l}\text { Intercept } \\
\mathrm{V}_{\mathrm{S} 1}(\mathrm{~m} / \mathrm{s})\end{array}$ & $\begin{array}{l}\text { Standard } \\
\text { deviation } \\
\ln \left(\mathrm{V}_{\mathrm{S}}\right)\end{array}$ \\
\hline $\begin{array}{l}\text { Appelscha, Boxtel, Drachten, } \\
\text { Eem, Peelo, Urk-Tynje } \\
\text { member }\end{array}$ & Peat & 0.25 & 122.7 & 0.27 \\
Appelscha & & & & \\
Boxtel & Clay & & & \\
Drachten & Clay & 0.25 & 267.7 & 0.20 \\
Drachten & Clay & 0.25 & 177.7 & 0.20 \\
Drente & Sandy clay and clayey sand & 0.25 & 146.9 & 0.20 \\
Drente & Fine sand & 0.25 & 221.4 & 0.20 \\
Drente & Medium sand & 0.25 & 225.9 & 0.20 \\
Drente, Gieten member & Coarse sand, gravel and shells & 0.25 & 239.8 & 0.20 \\
Drente, Gieten member & Fine sand & 237.5 & 0.20 \\
Drente, Gieten member & Medium sand & 0.25 & 278.7 & 0.20 \\
Eem & Coarse sand, gravel and shells & 0.29 & 295.9 & 0.20 \\
Naaldwijk & Clay & 0.26 & 194.4 & 0.20 \\
& Medium and coarse sand, gravel & 0.25 & 308.0 & 0.20 \\
Nieuwkoop Basal Peat & $\quad$ and shells & & & \\
Nieuwkoop Basal Peat & Clay & 0.25 & 141.2 & 0.27 \\
& Sandy clay and clayey sand, fine, & 0.25 & 170.7 & 0.27 \\
Urk, Tynje member & medium and coarse sand, gravel & & & \\
Urk, Tynje member & and shells & & & \\
Urk, Tynje member & Clay & 0.25 & 167.3 & 0.20 \\
Urk, Tynje member & Sandy clay and clayey sand & 0.25 & 194.4 & 0.20 \\
\hline & Fine sand and medium sand & 0.26 & 219.2 & 0.20 \\
& Coarse sand, gravel and shells & 0.26 & 265.1 & 0.20 \\
\hline & & & &
\end{tabular}

Not all units present in the Groningen region are represented in the SCPT data set. In those cases, either representative relations from similar units or expert estimates were used (e.g. Table 3). For example, all members from the Naaldwijk Formation were represented by the Naaldwijk $\mathrm{V}_{\mathrm{S}}$ distributions in Table 1 and 3. Additionally, the $\mathrm{V}_{\mathrm{S}}$ distributions of Nieuwkoop Holland Peat are assumed to be representative for all Holocene peats.

\subsection{MEI $V_{S}$ model}

Three-dimensional seismic reflection data was acquired in the 1980s by NAM for the purpose of imaging and characterisation of the Groningen gas reservoir. This legacy data set was used to constrain the $\mathrm{V}_{\mathrm{S}}$ model in the intermediate depth range. Surface waves are generally regarded as noise in the process of seismically imaging deep reflectors. Therefore, they are attenuated during acquisition of seismic data and suppressed during processing. The surface (and guided) waves, however, propagate along the surface and therefore contain useful information of the elastic properties of the near-surface. Survey techniques have been designed that use these types of waves (e.g. Park et al. 1999). Hence, inversion of these surface waves was used to derive a $\mathrm{V}_{\mathrm{S}}$ model. 
The Modal Elastic Inversion (MEI) method was used for the elastic near-surface model building. In essence, the MEI method is an approximate elastic Full Waveform Inversion method, in which the elastic wavefield is approximated by focusing on waves that propagate laterally through the shallow subsurface. These waves include the fundamental mode of the Rayleigh wave, its higher modes and guided waves. A limited number of horizontally propagating modes, characterized by lateral propagation properties and depthdependent amplitude properties, are taken into account to represent the near-surface elastic wavefield (Ernst, 2013). The objective in the MEI approach is to find a model that minimizes the difference between the observed data (Rayleigh waves) and the forward modelled data.

The pre-processing applied to the data prior to Modal Elastic Inversion was restricted to applying a high-cut filter and data selection of those data traces that contain the Rayleigh waves. For efficiency, the data set was split in large overlapping rectangular areas, which were inverted independently. Within one area, all data are inverted simultaneously. The resulting $\mathrm{V}_{\mathrm{S}}$ models are merged afterwards. The starting model was a laterally invariant vertical gradient, which was subsequently updated during the inversion. All lateral variations in the resulting $\mathrm{V}_{\mathrm{S}}$ model were introduced by the inversion. Generally, the uncertainty in $\mathrm{V}_{\mathrm{S}}$ values in the resulting $\mathrm{V}_{\mathrm{S}}$ model is estimated to be 5-10\%.

The vertical resolution of the resulting $\mathrm{V}_{\mathrm{S}}$ model is limited and the maximum depth range to which $V_{S}$ in this case can be reliably estimated is approximately $120 \mathrm{~m}$ below the surface. This is due to the seismic data acquisition design and consequently the narrow frequency band in which the surface waves are unaffected and still present in the data. The surface seismic data was acquired in 1988 with mostly (buried) dynamite sources and to a lesser extent with vibroseis sources (in cities) or airgun sources (in lakes and offshore), and recorded with $10 \mathrm{~Hz}$ vertical geophones. The seismic data acquisition was designed for deep imaging of the Groningen reservoir with a typical orthogonal geometry with line spacing of $250-500 \mathrm{~m}$ and group spacing of $50 \mathrm{~m}$. The receiver group arrays were designed to suppress and distort Rayleigh waves with wavelengths less than approximately $80 \mathrm{~m}$. The effect of the geophone arrays on the surface waves is illustrated in Fig. 6, in which a typical seismic record is displayed with full frequency band and with a frequency high-cut filter applied to $3 \mathrm{~Hz}$. Above $3 \mathrm{~Hz}$ the receiver arrays have distorted and aliased the Rayleigh waves, and below $1 \mathrm{~Hz}$ the Rayleigh waves have become too weak to be observed on the seismic records. The application of the MEI method to the data was
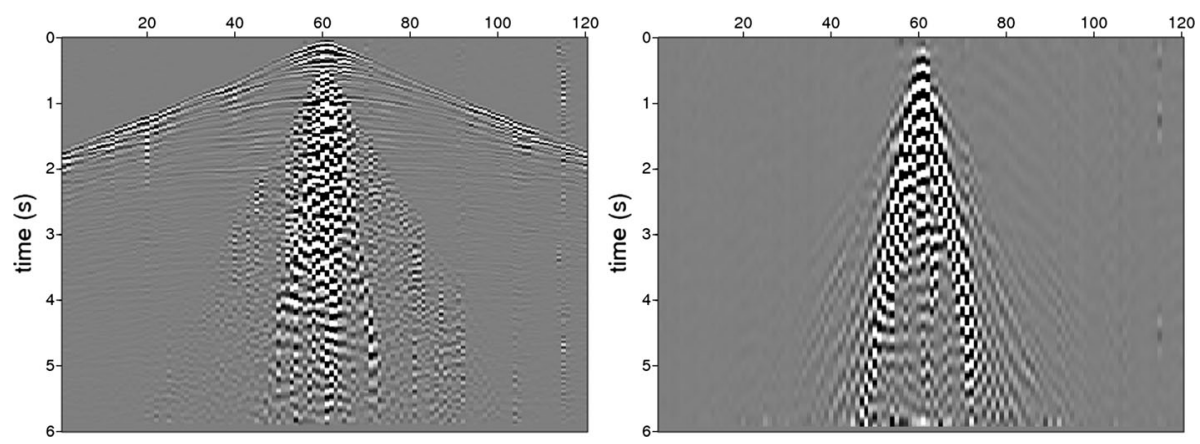

Fig. 6 Typical input seismic record from the Groningen 3D seismic reflection data with full frequency band (left) and high-cut filter at $3 \mathrm{~Hz}$ (amplified $\times 10$, right). The numbers on the $\mathrm{x}$-axis indicate trace numbers 
therefore restricted to the bandwidth from 1 to $3 \mathrm{~Hz}$, and to those recorded traces on which the Rayleigh waves were recorded.

The narrow temporal bandwidth results in a narrow range of wavelengths (roughly between $\sim 70 \mathrm{~m}$ and $\sim 500 \mathrm{~m}$ ). The penetration depth of the Rayleigh wave depends on the wavelength: the short wavelengths are sensitive to the shallow subsurface velocities, whereas the long wavelengths are more sensitive to the deeper velocities. The narrow range of wavelengths and especially the lack of short wavelengths therefore results in limited resolving power for the very shallow subsurface velocities. A typical depth resolution kernel of the fundamental mode of the Rayleigh wave is shown in Fig. 7. The high frequencies (right side of the plot) are more sensitive to the shallow layers, while the low frequencies (left side of the plot) are more sensitive to the deeper layers. The maximum penetration depth is $\sim 120 \mathrm{~m}$ and there is a limited resolving power of velocities in the shallow layers of the model $(0-20 \mathrm{~m})$.

The convergence of the inversion is verified using the normalized root-mean-square (RMS) misfit between the model and the data for each seismic shot (Fig. 8). The normalized RMS misfit ranges from 0 (excellent convergence) to 100 (very poor convergence). Generally, Fig. 8 shows that the normalized RMS misfit is good, but there are several areas with large misfits (denoted by red outlines). These larger misfits are linked to the source types used during the seismic acquisition. In and around cities or highways vibroseis sources were used and airguns were used in lakes. Both source types do not contain the low frequencies required for the inversion. The estimation of the shear-wave velocity model in these areas might be hampered by these conditions. In other areas, the seismic records were acquired using buried dynamite sources and show a much better

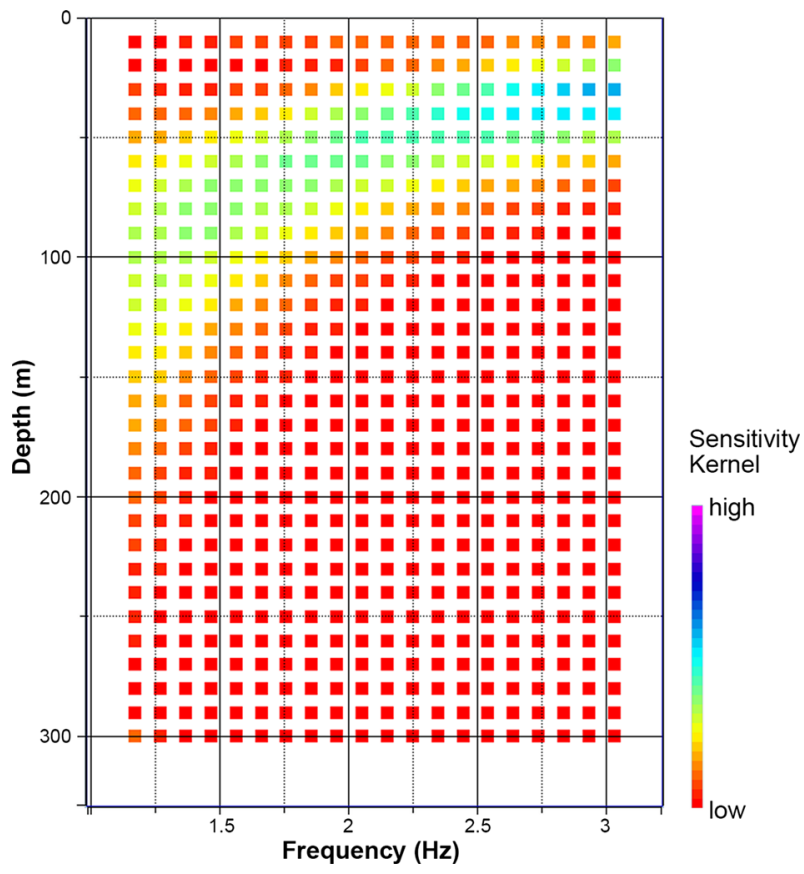

Fig. 7 Representative depth sensitivity kernel for the fundamental mode of the Rayleigh wave as a function of depth and frequency. Red indicates low sensitivity, blue indicates high sensitivity 


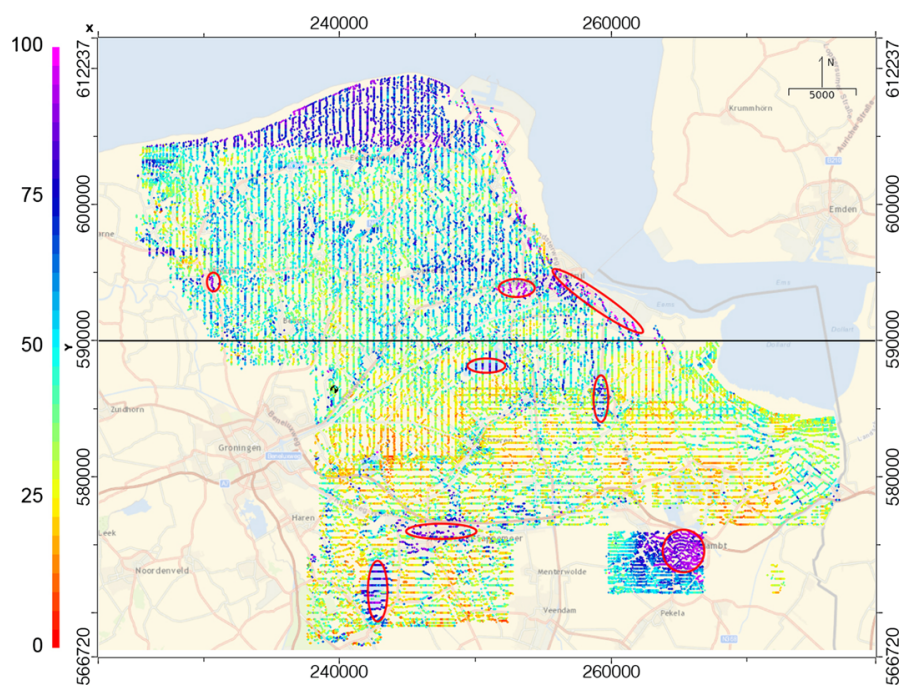

Fig. 8 Normalized RMS misfit per shot record. Red outlines indicate areas with large misfit due to seismic acquisition source types (vibroseis and airguns)

RMS. The area in the north is characterized by a high ambient noise level that cannot be modelled and therefore shows up as a relatively large RMS misfit.

The inversion resulted in a $\mathrm{V}_{\mathrm{S}}$ model over the area where $3 \mathrm{D}$ seismic data was available, and therefore does not cover the full extent of the area of interest. Horizontally, the $V_{S}$ model is gridded on the same $100 \mathrm{~m} \times 100 \mathrm{~m}$ grid as the GeoTOP model. Vertically, the $\mathrm{V}_{\mathrm{S}}$ model is defined at $10 \mathrm{~m}$ depth intervals. An example of a depth slice at $65 \mathrm{~m}$ depth is shown in Fig. 9. The MEI $V_{S}$ model shows distinct zones of relatively high and relatively low $\mathrm{V}_{\mathrm{S}}$ values in patterns that resemble geological features, such as buried valleys. These structures can also be recognized in a cross-section from West to East in the centre of the field (Fig. 10). The cross-section also shows the vertical smoothness of the model.

\subsection{Sonic $V_{S}$ model}

For larger depths, $\mathrm{V}_{\mathrm{S}}$ is derived from the seismic data that was collected to image the reservoir. One component of the processing of seismic data for imaging is the application of pre-stack depth migration (Yilmaz 2001), which among others moves dipping reflectors to their true positions. This procedure requires a velocity model, the so-called Pre-Stack Depth Migration Velocity model (PSDM velocity model). There are more than 500 wells in the Groningen field. Data from these wells were available for this project. Sonic logs, providing $\mathrm{V}_{\mathrm{P}}$, were measured in 70 of them. In several wells, $\mathrm{V}_{\mathrm{S}}$ was measured as well over a limited depth range. In two wells both $V_{P}$ and $V_{S}$ were measured over the entire North Sea Supergroup. Sonic logs and well markers for key horizons are used to construct a depth-calibrated, high-resolution P-wave $\left(\mathrm{V}_{\mathrm{P}}\right)$ model over the entire field. There is sufficient coverage of sonic logs for depths larger than $200 \mathrm{~m}$, but for shallower depths, the accuracy of the $\mathrm{V}_{\mathrm{P}}$ model is reduced.

The PSDM velocity model is used as input $V_{P}$ model for the North Sea Supergroup. Site response calculations, however, require information in terms of $V_{S}$ instead of $V_{P}$. Hence, 
Fig. 9 Depth slice through the MEI $\mathrm{V}_{\mathrm{S}}$ model at a depth of NAP-65 m
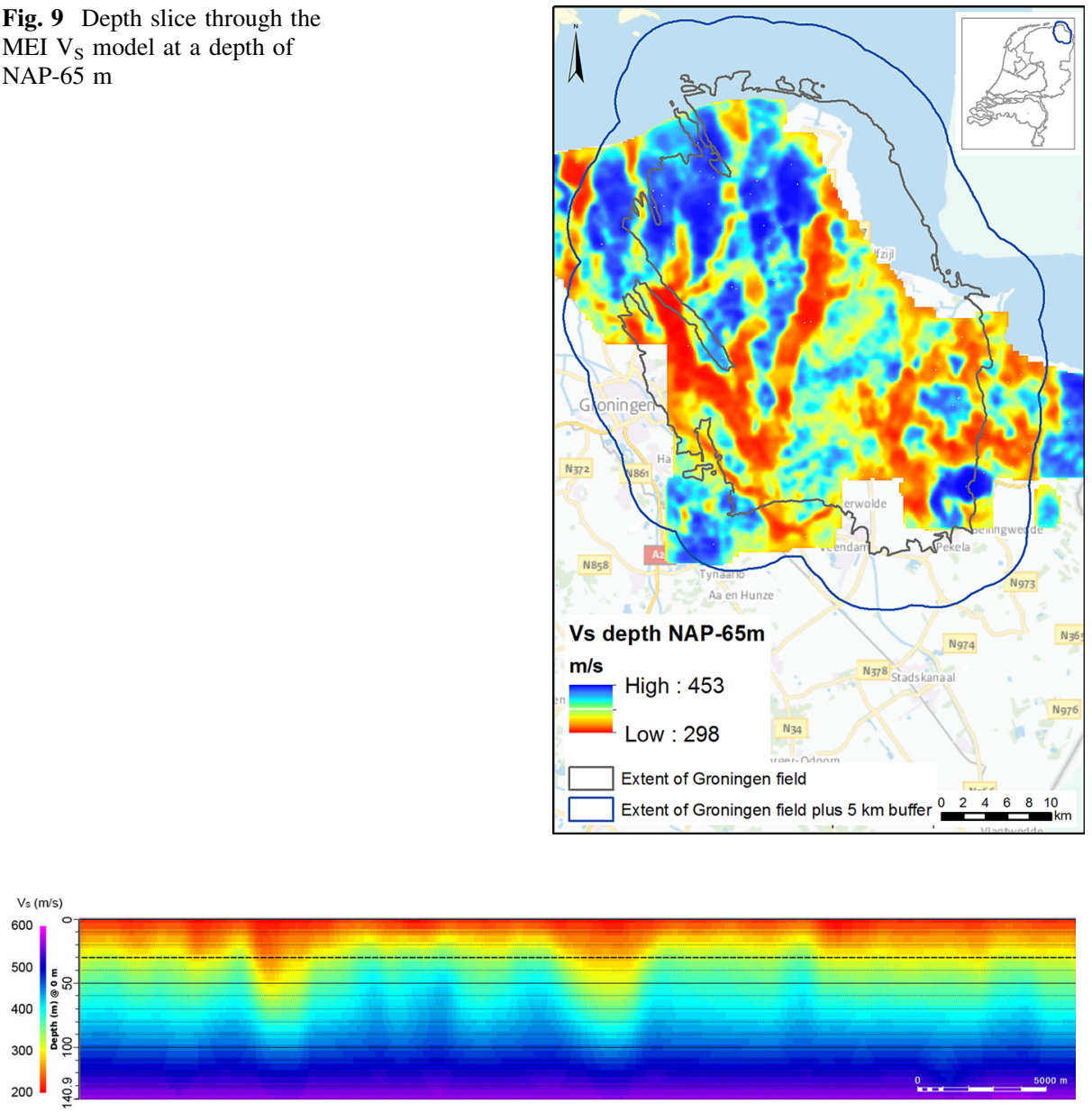

Fig. 10 Cross section through the MEI $\mathrm{V}_{\mathrm{S}}$ model, from west to east at the centre of the field. The vertical scale is exaggerated

the PSDM $V_{P}$ values are converted to $V_{S}$ using $V_{P} / V_{S}$ relations from the two well $\operatorname{logs}$ where both $V_{P}$ and $V_{S}$ were measured over the entire North Sea Supergroup (Fig. 11). The measurements of $\mathrm{V}_{\mathrm{P}}$ and $\mathrm{V}_{\mathrm{S}}$ start below the depth of the conductor in the well, at $\sim 60-75 \mathrm{~m}$. The ratio between $\mathrm{V}_{\mathrm{P}}$ and $\mathrm{V}_{\mathrm{S}}$ shows a linear decrease with depth in the Upper North Sea Group, while it is more or less constant in the Lower North Sea Group (Fig. 11). The linear relationship to convert $\mathrm{V}_{\mathrm{P}}$ into $\mathrm{V}_{\mathrm{S}}$ for the Upper North Sea Group is given by:

$$
V_{S}=\frac{V_{P}}{(4.7819-0.0047 * \mathrm{Z})}
$$

where $\mathrm{Z}$ is the depth in metres. The corresponding Poisson's ratio in the Upper North Sea Group generally varies between 0.45 and 0.47 . The constant relation to convert $V_{P}$ into $V_{S}$ for the Lower North Sea Group is given by: 

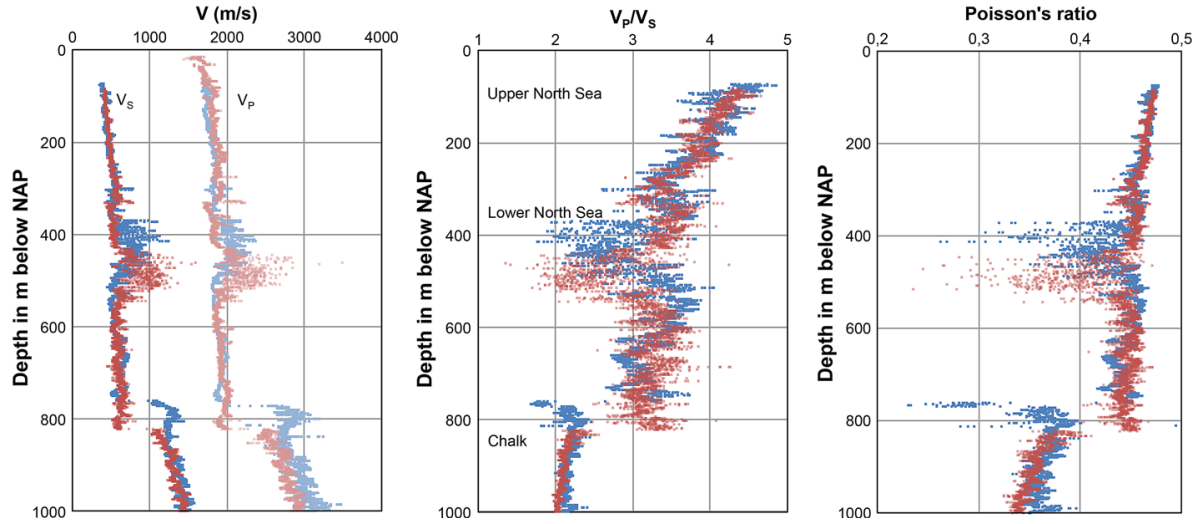

Fig. $11 \mathrm{~V}_{\mathrm{P}}$ and $\mathrm{V}_{\mathrm{S}}$ profiles (left) and the $\mathrm{V}_{\mathrm{P}} / \mathrm{V}_{\mathrm{S}}$ ratio (middle) and Poisson's ratio (right) for two deep wells in the Groningen field. BRW-5 in blue symbols, ZRP-2 in red symbols

$$
V_{S}=\frac{V_{P}}{3.2}
$$

This corresponds to a Poisson's ratio of 0.446 .

The Sonic $\mathrm{V}_{\mathrm{S}}$ model was discretised in layers of $25 \mathrm{~m}$ thickness and on a grid identical to the $100 \mathrm{~m} \times 100 \mathrm{~m}$ cells of the GeoTOP model. A cross section of the sonic $\mathrm{V}_{\mathrm{S}}$ model through the centre of the field is shown in Fig. 12. The $V_{S}$ inversion which is present in the Lower North Sea Group at depths of $\sim 500 \mathrm{~m}$ is caused by the Brussels sand. Locally, this sand is cemented, leading to high $\mathrm{V}_{\mathrm{S}}$.

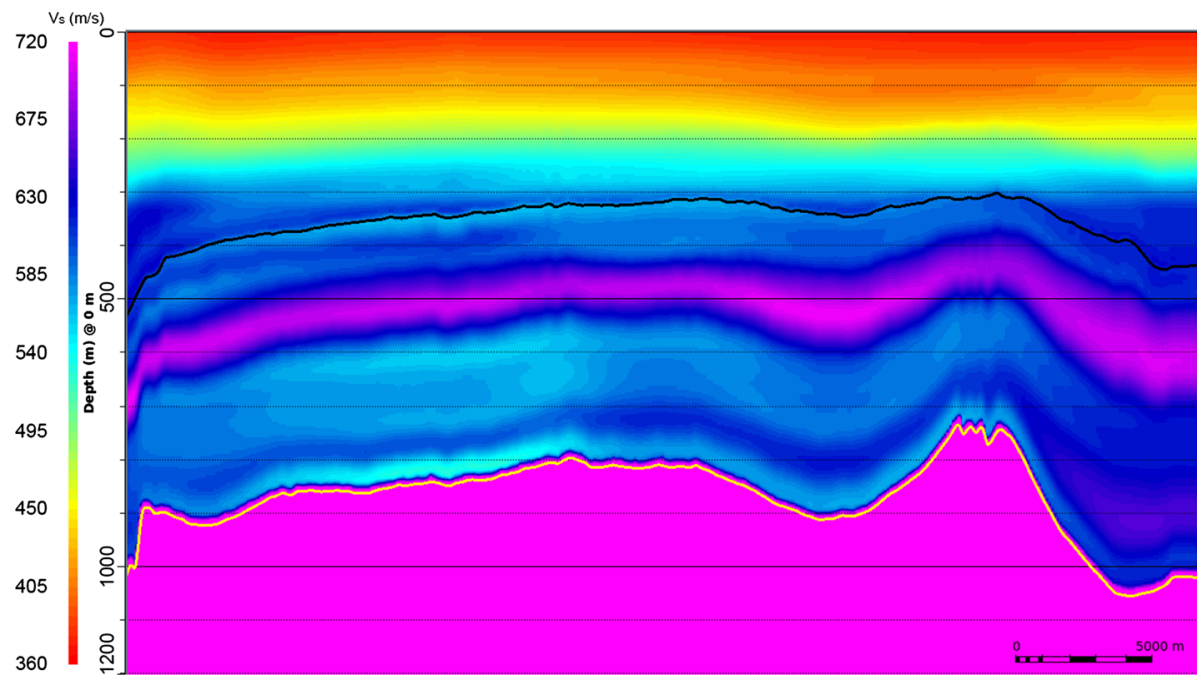

Fig. 12 Cross section through the Sonic $V_{S}$ model, from west to east at the centre of the field. The vertical scale is exaggerated. The base of the Upper North Sea Group is indicated by the black line; the base of the Lower North Sea Group by the thin yellow line 


\section{Generation of $V_{S}$ profiles}

\subsection{Splicing of the final $V_{S}$ models}

The three $\mathrm{V}_{\mathrm{S}}$ models are spliced in order to obtain $\mathrm{V}_{\mathrm{S}}$ profiles from the surface to the reference baserock horizon at the base of the North Sea Supergroup for each location in the field. The top part, from the surface to NAP-50 m, consists of the GeoTOP $\mathrm{V}_{\mathrm{S}}$ model. The MEI $\mathrm{V}_{\mathrm{S}}$ model is appended between NAP-50 m and a maximum of NAP-120 m. The layer thicknesses in the MEI $\mathrm{V}_{\mathrm{S}}$ depth range are taken from the geological scenarios of the geological model below $50 \mathrm{~m}$ (Sect. 5). The maximum thickness of layers in this depth range is $10 \mathrm{~m}$.

The extent of the MEI model is smaller than the extent of the area of interest, comprising of the Groningen field with a $5 \mathrm{~km}$ buffer. For regions outside the MEI range, the average MEI $V_{S}$ for a depth slice was selected as an estimate of $V_{S}$. In effect, this yielded an increasing $V_{S}$ model with depth, but without detailed channel-like structures.

The transition between the MEI and the sonic $\mathrm{V}_{\mathrm{S}}$ model is chosen at the depth where the two $V_{S}$ profiles intersect. This choice avoids velocity inversions at the transition. The layer thicknesses in the sonic $V_{S}$ range are taken from the geological scenarios of the geological model below $50 \mathrm{~m}$ (Sect. 5) with a maximum thickness of $25 \mathrm{~m}$. The reference rock horizon is represented by the base of the North Sea Supergroup. At this level, there is an impedance contrast as $\mathrm{V}_{\mathrm{S}}$ jumps from $\sim 600 \mathrm{~m} / \mathrm{s}$ (on average) just above this level to $1400 \mathrm{~m} / \mathrm{s}$ (on average) just below this level. Examples of typical $\mathrm{V}_{\mathrm{S}}$ profiles constructed from the three $V_{S}$ models are shown in Fig. 13. In total, approximately $140,000 \mathrm{~V}_{\mathrm{S}}$ profiles were generated.

\subsection{Randomisation of $V_{S}$ profiles}

The spatial variability within each geological zone (Sect. 5) needs to be captured in the site response analyses. To this end, randomisation was applied in the site response calculations to the soil composition, input motions (Rodriguez-Marek et al. 2017) and to the $\mathrm{V}_{\mathrm{S}}$ profiles in the GeoTOP depth range. Randomisation of soil composition is achieved by assuming that the collection of GeoTOP voxel-stacks within one geological zone represent the likely
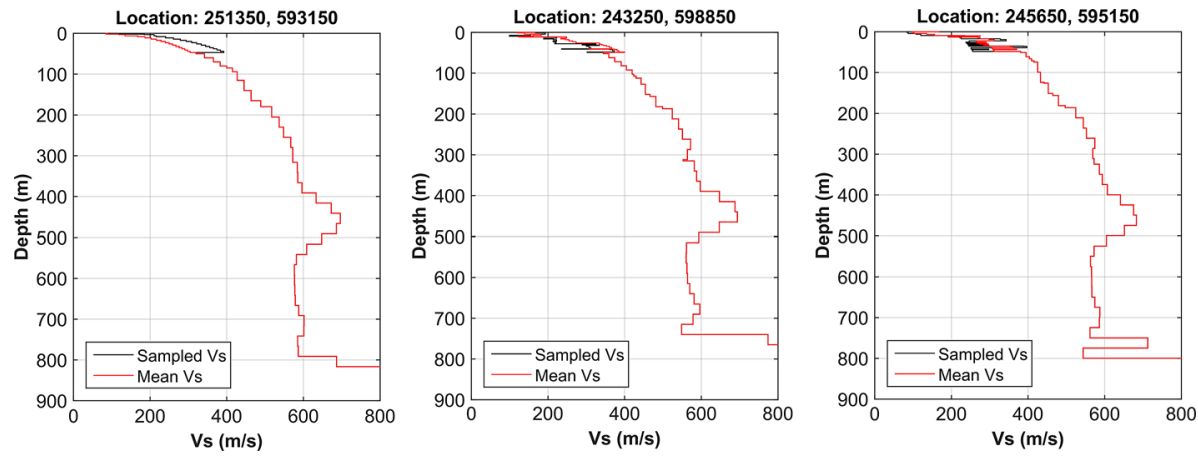

Fig. 13 Examples of $V_{S}$ profiles over the full depth range, with sampled and mean $V_{S}$ in the top $50 \mathrm{~m}$ and MEI and Sonic $V_{S}$ below $50 \mathrm{~m}$. The sampling is described in Sect. 4.2. The $\mathrm{V}_{\mathrm{S}}$ at reference rock horizon $(1400 \mathrm{~m} / \mathrm{s})$ is out of the horizontal scale 
successions of units within that zone. The procedure to develop randomised GeoTOP $\mathrm{V}_{\mathrm{S}}$ profiles is shown in Figs. 14 and 15. Shear-wave velocity profiles were calculated for each voxel-stack in the GeoTOP model. For each unit in the voxel-stack (Fig. 14a,b), the corresponding $\mathrm{V}_{\mathrm{S}}$ relation is selected from Tables 1 , 2, or 3 . A sensitivity study indicated that the $0.5 \mathrm{~m}$ layering of GeoTOP created unrealistic site response results. Therefore, the GeoTOP layers were resampled into layers of $1.0 \mathrm{~m}$, by examining the two voxels within every metre and selecting one of the voxels at random (Fig. 14c-e). Next, consecutive voxels of the same unit were merged into one layer up to a maximum thickness of $3.0 \mathrm{~m}$ (Fig. 14f,g). The maximum thickness of $3.0 \mathrm{~m}$ was imposed to preserve the confining stress-dependence of $\mathrm{V}_{\mathrm{S}}$.

Within one voxel-stack and one unit of stratigraphy and lithological class we assume full correlation of $\mathrm{V}_{\mathrm{S}}$. This means that all layers of a given unit within one voxel-stack are based on one sample of $\mathrm{V}_{\mathrm{S}}$ from the $\mathrm{V}_{\mathrm{S}}$ distribution of this unit (i.e. from Tables 1, 2, or 3). Within one voxel-stack and between different units we assume a correlation coefficient $\rho$ of 0.5 . In order to avoid $\mathrm{V}_{\mathrm{S}}$ profiles that have extremely low or extremely high (and therefore unrealistic) $V_{S}$ values, the distributions were truncated at two standard deviations. This truncation follows common practice in site response analyses of nuclear facilities (EPRI 2013). To compensate for the truncation, the $V_{S}$ values are sampled from a distribution with a standard deviation that is increased by $16 \%$. This value corresponds to the value that would render a truncated distribution with the desired (target) standard deviation. A correlated sampling approach was implemented largely following Toro (1995). The $\mathrm{V}_{\mathrm{S}}$ distributions were standardized in order to be able to sample in a correlated way between units having different $\mathrm{V}_{\mathrm{S}}$ distributions (different average and standard deviation of $\ln V_{S}$ ). Truncation was implemented as follows:

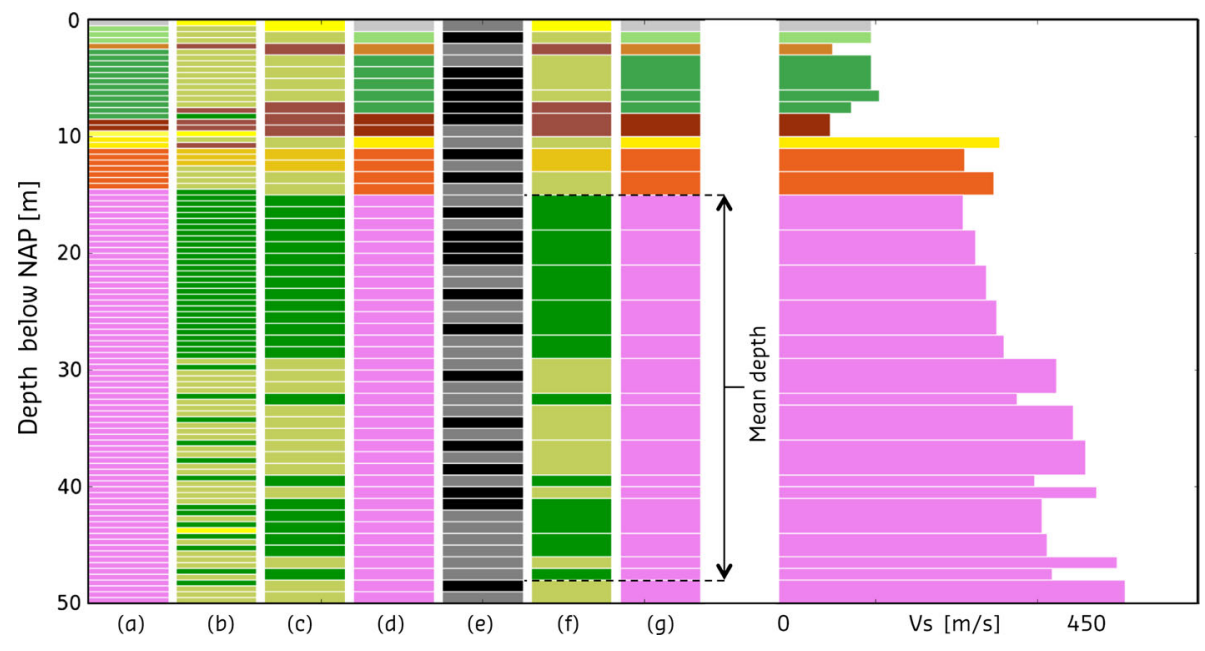

Fig. 14 Example of GeoTOP voxel-stack processing. From left to right: (a) original GeoTOP stratigraphic units; $(b)$ original GeoTOP lithological classes; $(c)$ resampled lithological classes into layers of $1.0 \mathrm{~m}$ thickness; $(d)$ resampled stratigraphic units into layers of $1.0 \mathrm{~m}$ thickness; $(e)$ random selector used to select the upper (grey) or lower (black) voxel; $(f)$ merged lithological classes with a maximum thickness of $3.0 \mathrm{~m}$; $(\mathrm{g})$ merged stratigraphic units with a maximum thickness of $3.0 \mathrm{~m}$. For the clays (green) of the Peelo Formation (purple), the mean depth of the unit is indicated. Far right: bar graph of the sampled shear-wave velocity profile assigned to the voxels by applying the routine from Fig. 15 to voxel-stacks $(f)$ and $(g)$ 
1. Draw a random sample $\ln \left(V_{S_{\text {sample }}}\right)$ from a normal distribution with

$$
\mu=\ln \left(V_{S_{\text {mean }}}\right) \quad \text { and } \quad \sigma^{*}=1.16 \sigma_{\ln \mathrm{V}_{\mathrm{S}}}
$$

2. Standardise to a distribution with $\mu=0$ using

$$
\ln \left(V_{S_{\text {sample }_{\text {standardized }}}}\right)=\frac{\left(\ln \left(V_{S_{\text {sample }}}\right)-\mu\right)}{\sigma^{*}}
$$

3. Repeat steps 1 and 2 until

$$
\left|\ln \left(V_{S_{\text {sample }_{\text {standardized }}}}\right)\right|<2.0
$$

The random sample for each unit is taken at the average depth of occurrence of this unit in the voxel-stack. For the confining stress-dependent $\mathrm{V}_{\mathrm{S}}$ relations in Table 1 the standard deviation is related to the distance to average $\ln \left(\frac{\sigma_{o}^{\prime}}{p_{a}}\right)$. In order to avoid sampling in the confining stress range either outside the range defined by the data, or always at the tails of the distribution which might results in relatively large standard deviation, the random sample $\ln \left(V_{S_{\text {sample }}}\right)$ is taken at the average depth of occurrence of the particular unit, assuming that this is comparable to the average confining stress.

When moving to the next unit in the voxel-stack, correlated sampling is applied, again at the average depth of occurrence of the next unit. The correlated sampling is implemented as follows:

1. Draw an auxiliary variable $b$ (needed for standardized and truncated distribution) from a normal distribution with $\mu=0$ and $\sigma=1.16$.

2. Repeat step 1 until $|b|<2.0$.

3. Calculate $\ln \left(V_{S_{\text {sample }_{\text {standardized }}}}\right)$ correlated to the previous layer using the correlation coefficient $\rho$ and auxiliary variable b using:

$$
\ln \left(V_{S_{\text {sample }_{\text {standardized }}}}\right)=\rho \ln \left(V_{S_{\text {previouslayer }_{\text {standardized }}}}\right)+b \sqrt{\left(1-\rho^{2}\right)}
$$

4. Transform $\ln \left(V_{S_{\text {sample }_{\text {standardized }}}}\right)$ to $\ln \left(V_{S_{\text {sample }}}\right)$ using:

$$
\ln \left(V_{S_{\text {sample }}}\right)=\mu+\sigma^{*} \ln \left(V_{S_{\text {sample }} \text { standardized }}\right)
$$

where $\mu$ is the mean $\mathrm{V}_{\mathrm{S}}$ value at that depth.

5. Use $\ln \left(V_{S_{\text {sample }_{\text {standardized }}}}\right)$ as $\ln \left(V_{\text {previouslayer }_{\text {standardized }}}\right)$ in Eq. (7) in the calculation of the next unit.

Using the above described procedure, the truncated and correlated $\ln V_{S}$ is sampled for each unit at one depth per unit. In order to determine the shear-wave velocities at other depths of this unit in the voxel stack, the updated intercept $\ln V s_{2}$ is determined using the slope $n$ of the corresponding distribution and $\ln \left(V_{S_{\text {sample }}}\right)$ from Eq. 8 for this unit using: 
Fig. 15 Scheme for sampling of $\mathrm{V}_{\mathrm{S}}$. 'strat-lith' is short for the combination of stratigraphic unit and lithological class

$$
\ln V s_{2}=\ln V_{S_{\text {sample }}}-\left(n \ln \left(\frac{\sigma_{o}^{\prime}}{p_{a}}\right)_{\text {ataveragedepth }}\right)
$$

Finally, the $\ln V_{S}$ values at all other depths (and thus confining stresses) within this voxel-stack of this unit are calculated using:

$$
\ln V s=\ln V s_{2}+n \ln \left(\frac{\sigma_{o}^{\prime}}{p_{a}}\right)
$$

In effect this means that only $\ln V s_{1}$ and not the slope $n$ is randomized in Eq. 1.

Examples of randomized $V_{S}$ profiles are shown in Fig. 16. For reference, the units and the profiles based on the mean $\mathrm{V}_{\mathrm{S}}$ relation are included as well. For uniform units, the confining stress dependent increase in $\mathrm{V}_{\mathrm{S}}$ is apparent (e.g. in the left panel of Fig. 16). The correlated sampling ensures that the jumps in $\mathrm{V}_{\mathrm{S}}$ between units are not unrealistically large. In some cases, almost the entire profile is sampled in the low side of the mean (e.g. middle panel of Fig. 16). Because of a correlation coefficient of 0.5 , jumps from relatively high sampled $V_{S}$ to relatively low sampled $V_{S}$ between units is still possible (e.g. right panel of Fig. 16).

\section{Zonation and layering}

The geological cross section of Fig. 2 shows that the subsurface in Groningen is heterogeneous. As a consequence, the properties that dictate the response to earthquake shaking will be spatially variable. However, for practical considerations the site response analyses were conducted for a finite number of zones within the Groningen field (Rodriguez-Marek et al. 2017). Hence, we defined zones of geologically similar build-up to accommodate for the heterogeneity of the subsurface. These zones were used as a starting point for the site response zonation (Rodriguez-Marek et al. 2017).

Several sources of information were available for the definition of the geological zones: the high resolution 3D geological model GeoTOP (Stafleu et al. 2011; Stafleu and Dubelaar 2016), 19,082 borehole descriptions from the DINO database (www.dinoloket.nl), 5674 cone penetration tests, the Digital Geological Model of the Netherlands (DGM, Gunnink et al. 2013), the REgional Geohydrological Information System II (REGIS II, Vernes and van Doorn 2005), the digital terrain model AHN (open data, www.ahn.nl) and paleogeographic maps (Vos and Knol 2015; Vos et al. 2011).

Because of the difference in resolution and depth range of the various geological sources, the region of Groningen has been divided into zones of similar geology for two depth ranges (Kruiver et al. 2015). Between the surface and the maximum depth of GeoTOP (NAP-50 m), the geological zones are defined based on characteristic successions. The model consists of a geological zonation map (Fig. 17) and the GeoTOP voxels with stratigraphic and lithoclass information. This zonation was applied to the site response results (Rodriguez-Marek et al. 2017), because of the large contribution of the shallowest deposits to the site response. 


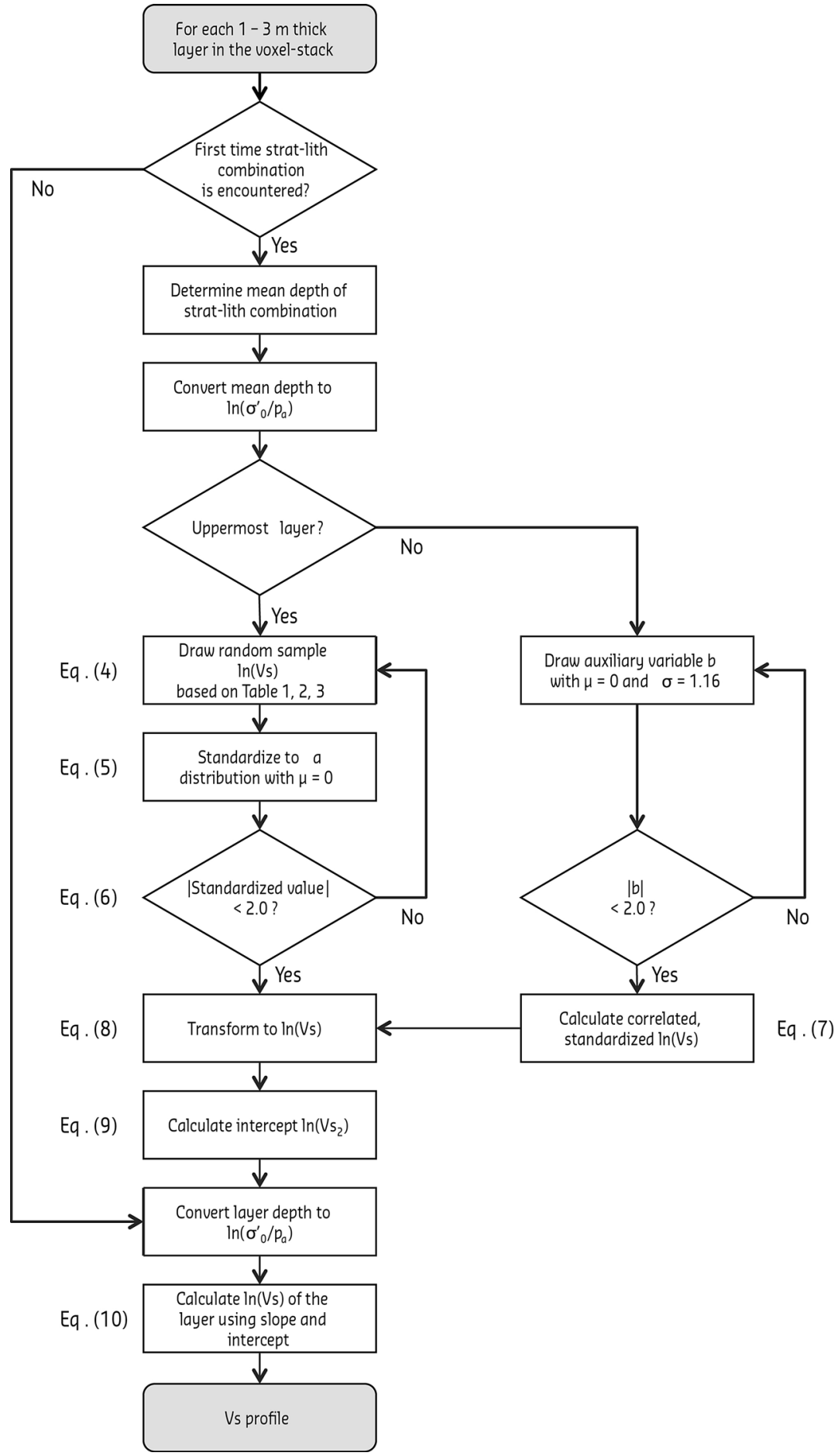



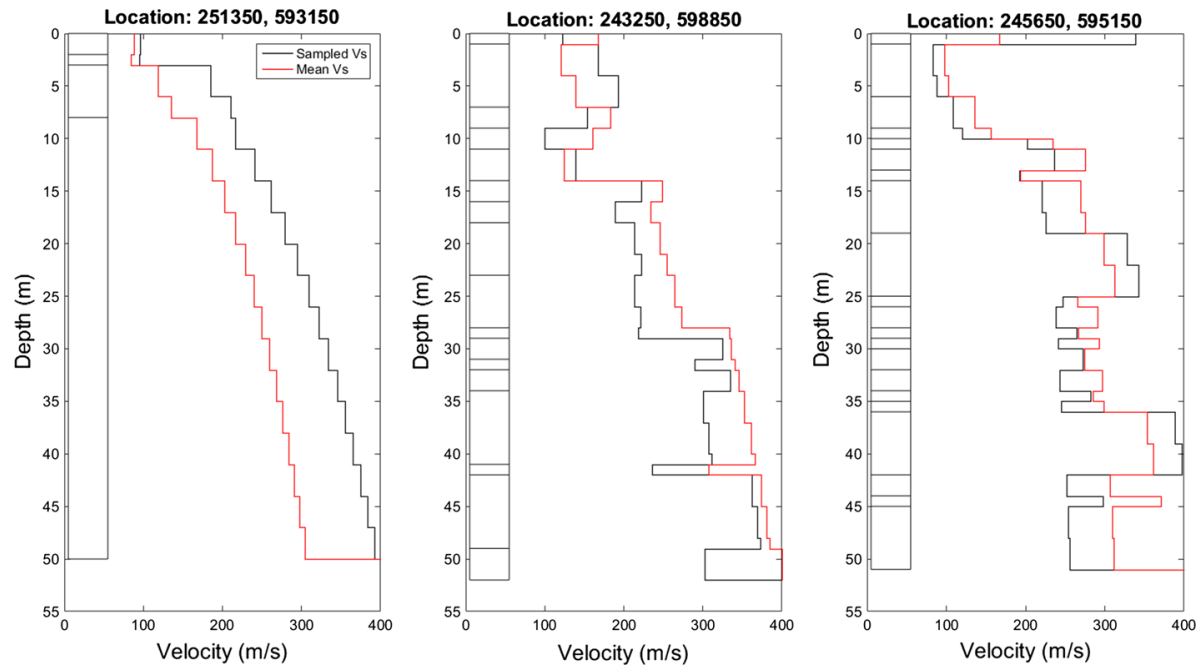

Fig. 16 Three examples of randomized $\mathrm{V}_{\mathrm{S}}$ profiles (black line) and mean $\mathrm{V}_{\mathrm{S}}$ profiles (red lines), at the same locations as Fig. 13. The column at the left of each graph indicates the units in the voxel-stack. Left: example of homogeneous voxel-stack with only 4 units of stratigraphy-lithology. Middle and right: examples of more heterogeneous voxel-stacks

In addition to the $\mathrm{V}_{\mathrm{S}}$ profiles, site response analyses require the assignment of nonlinear properties to each layer. This assignment is based on the soil type for each layer (e.g. using Darendeli 2001 or Menq 2003). For the near surface layers, the stratigraphic and lithoclass information from the GeoTOP model is used to assign soil types to each layer. The deeper geological structures are different from the shallow structures, hence a different geological zonation map applies for the depth range between NAP-50 m and the base of the Upper North Sea Group. The layer and composition information for this depth range which are needed for assigning appropriate nonlinear properties to each layer is represented by characteristic scenarios for subsurface successions for each zone, including a probability of encountering each scenario in that zone. In the site response calculations, the Lower North Sea Group was considered to behave linearly (Rodriguez-Marek et al. 2017). Therefore, details on the composition of these layers, beyond its $V_{S}$ value, are not needed. The full layer profile for each location (X, Y coordinate on the GeoTOP grid) is a combination of the GeoTOP layers of stratigraphy and lithoclass, appended with one of the deeper scenarios while taking into account the probabilities of each scenario on the deeper geological zones.

\section{$6 \mathrm{~V}_{\mathrm{S30}} \mathrm{map}$}

The time-averaged shear-wave velocity over the upper $30 \mathrm{~m}$ of a profile $\left(\mathrm{V}_{\mathrm{S} 30}\right)$ is used as an input to some of the components of the ground motion model for the Groningen region (Bommer et al. 2017) The GeoTOP $\mathrm{V}_{\mathrm{S}}$ model enables the determination of a $\mathrm{V}_{\mathrm{S} 30}$ map. This map is also relevant for the new building codes in the Netherlands. A $V_{S}$ profile is calculated between the surface and $30 \mathrm{~m}$ depth following the scheme described in Sect. 4, except that the layers of $0.5 \mathrm{~m}$ thickness of GeoTOP have been preserved. The $\mathrm{V}_{\mathrm{S} 30}$ is then calculated from the $\mathrm{V}_{\mathrm{S}}$ profile as the harmonic mean. This procedure was repeated 100 
Fig. 17 Geological zonation map. Similar colours indicate similar geological successions in the shallow depth range

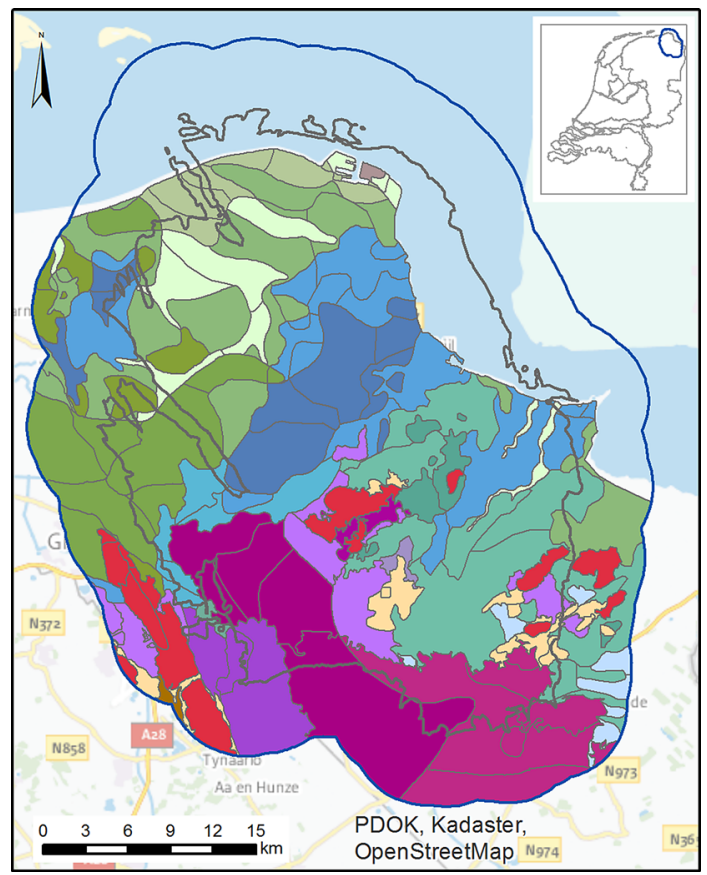

times with a different initial random sample for each voxel-stack, which provided 100 estimates of $\mathrm{V}_{\mathrm{S} 30}$ for each GeoTOP grid cell.

The average and standard deviation of $\mathrm{V}_{\mathrm{S} 30}$ values for each geological zone were calculated from all $V_{\mathrm{S} 30}$ values within that zone. For the entire field, the average $V_{\mathrm{S} 30}$ based on all $\mathrm{V}_{\mathrm{S} 30}$ realisations is $207 \mathrm{~m} / \mathrm{s}$ with a standard deviation of $48 \mathrm{~m} / \mathrm{s}$. The $\mathrm{V}_{\mathrm{S} 30}$ maps with zonation are shown in Fig. 18 for mean and standard deviation of $\mathrm{V}_{\mathrm{S} 30}$. The data are plotted in coloured bins in these figures; the $\mathrm{V}_{\mathrm{S} 30}$ data per zone is available in Online Resource 1 . The average and median $\mathrm{V}_{\mathrm{S} 30}$ are very similar, with a maximum difference of $5 \mathrm{~m} / \mathrm{s}$. The maps show a distinct pattern in $\mathrm{V}_{\mathrm{S} 30}$ that is related to geology. The northern part of the region contains the thickest layers of soft Holocene deposits, with overall low $\mathrm{V}_{\mathrm{S} 30}$ values. Channel structures can be recognised, e.g. in the eastern part. The southern part consists of Pleistocene deposits which are generally stiffer (but still relatively soft soil), which is reflected in the higher $\mathrm{V}_{\mathrm{S} 30}$ values. The Hondsrug (the sand ridge on which the city of Groningen is situated) stands out as a relatively high $\mathrm{V}_{\mathrm{S} 30}$ zone in the south west. Immediately east of the ridge is a channel that is filled with soft Holocene deposits. This is reflected by the low $\mathrm{V}_{\mathrm{S} 30}$ zone adjacent to the Hondsrug. The right panel of Fig. 18 shows that the standard deviation of $\mathrm{V}_{\mathrm{S} 30}$ ranges from 25 to $54 \mathrm{~m} / \mathrm{s}$ between zones. Although the $\mathrm{V}_{\mathrm{S} 30}$ values are relatively low (soft soil), variation of $\mathrm{V}_{\mathrm{S} 30}$ within zones, expressed by the standard deviation, can be significant. The degree of variation in $\mathrm{V}_{\mathrm{S} 30}$ within the zones is not uniform across the entire field. In particular, within-zone variation is greater in the south where the average $\mathrm{V}_{\mathrm{S} 30}$ values are higher. 

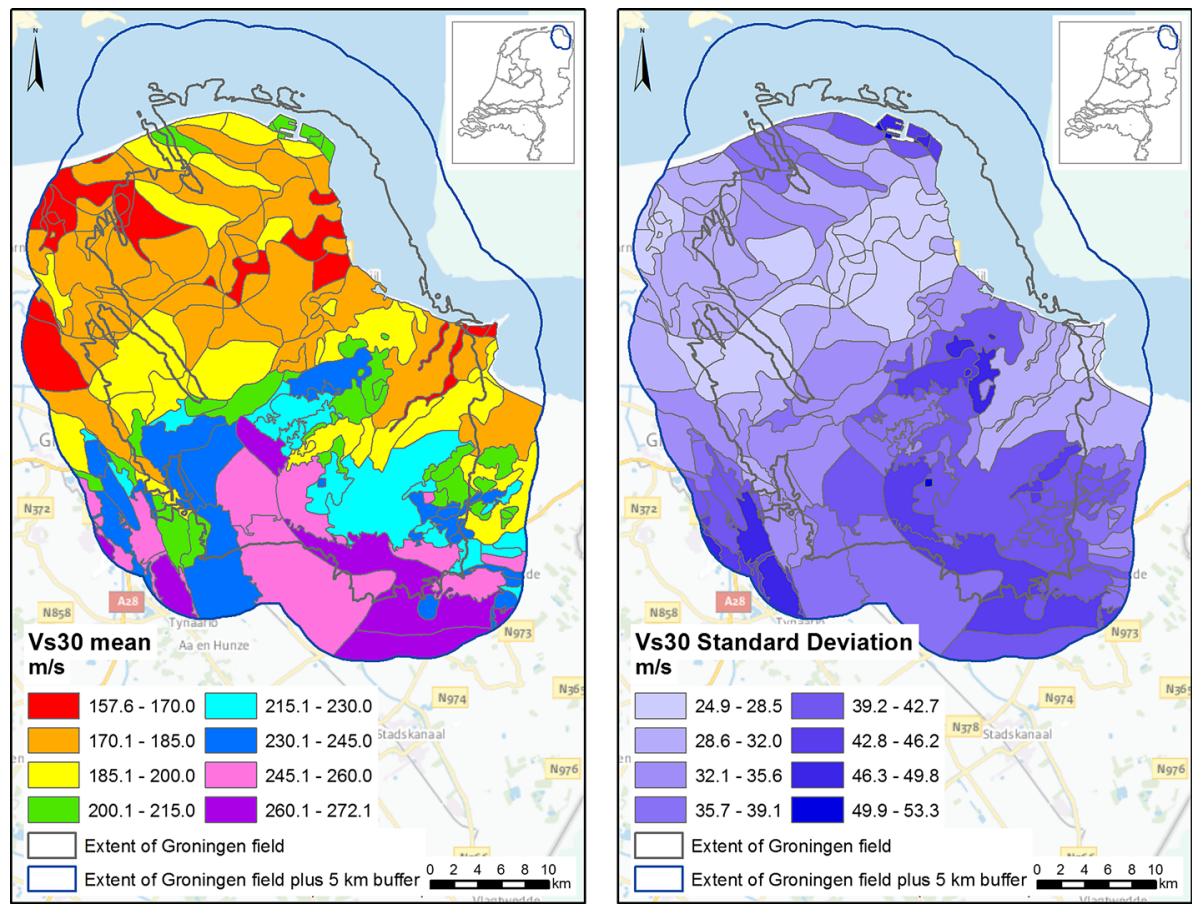

Fig. 18 Mean (left) and standard deviation (right) of $\mathrm{V}_{\mathrm{S} 30}$ for the Groningen region

\section{Discussion and conclusions}

In this paper a shear-wave velocity model is presented spanning the depth range from the surface to about $800 \mathrm{~m}$ depth as a starting point for site response analyses in the Groningen field. The combination of three different $\mathrm{V}_{\mathrm{S}}$ models (in terms of depth ranges) resulted in a model that is unique on this scale. Furthermore, a randomisation scheme for the shallow $V_{S}$ profiles (to $50 \mathrm{~m}$ depth) was developed, taking into account the geological characteristics of the subsurface. This randomisation is required to determine the probabilistic amplification factors that feed into the seismic hazard and risk analysis. To facilitate the randomisation of $\mathrm{V}_{\mathrm{S}}$, we derived $\mathrm{V}_{\mathrm{S}}$ relations for each unit of stratigraphy and lithology that is present in the region. Full correlation of $\mathrm{V}_{\mathrm{S}}$ is assumed within one unit in a vertical profile. Between units, however, partial correlation is assumed using a correlation coefficient of 0.5. Additionally, a microzonation model was constructed to account for geological heterogeneity.

The $\mathrm{V}_{\mathrm{S}}$ relations for the shallow depth range were based on SCPT data measured in the region. For some units there was insufficient data to determine a confining stress-dependent relation. Future fieldwork campaigns will increase the number of SCPTs available for this analysis. Additionally, there is a large number of CPTs $(\sim 5700)$ available in the region. This provides the opportunity to design a region specific $\mathrm{V}_{\mathrm{S}}$ relation based on both SCPTs and CPTs. When the CPTs are converted to synthetic $\mathrm{V}_{\mathrm{S}}$ profiles using relations that are calibrated on the SCPT-CPT data set, more units can be quantified. Rather than using standard classification methods (e.g. Robertson 1990), the adapted scheme is needed to accommodate soils such as peats and glacial clays. 
Additionally, the transition between the GeoTOP and MEI $\mathrm{V}_{\mathrm{S}}$ models is currently defined at one fixed depth, i.e. the maximum depth of the GeoTOP model. An alternative choice might be a transition level that varies in depth and is based on the location of channel structures or other geological features. However, to implement this approach the exact locations of these features needs to be known and these are currently not known in sufficient detail. Future subsurface models by TNO-Geological Survey of the Netherlands may include the required level of detail. In the current model, scenarios of stratigraphy were used below NAP-50 m to accommodate the uncertainty in locations of key geological features.

The model building presented in this paper represents a unique exercise in which a comprehensive set of geological, geotechnical, and geophysical data was used to build an extensive $3 \mathrm{D} \mathrm{V}_{\mathrm{S}}$ model for site response analyses. The construction of this deep and detailed $\mathrm{V}_{\mathrm{S}}$ model has enabled the incorporation of fully probabilistic, nonlinear site amplification functions into the estimation of surface ground motions (Rodriguez-Marek et al. 2017). In essence, an approach to including local site effects in seismic hazard analyses usually applied in site-specific studies for critical facilities can thus be applied to hazard and risk assessments for an entire region (Bommer et al. 2017).

Acknowledgements The geological zonation model was constructed by a large team of geologists from Deltares and TNO_-Geological Survey of the Netherlands: Ane Wiersma, Pieter Doornenbal, Tommer Vermaas, Renée de Bruijn, Marc Hijma, Freek Busschers, Marcel Bakker, Ronald Harting, Roula Dambrink, Willem Dabekaussen, Wim Dubelaar, Eppie de Heer, Jan Peeters. Veronique Marges provided numerous maps and Wim Dubelaar commented on the geological setting. We are very grateful to several individuals who have provided critical review and feedback at different stages of the project. We wish to express our gratitude to Ben Edwards, Rien Herber, Tijn Berends, Joep Storms, Adriaan Janszen, Karel Maron, Clemens Visser, Bernard Dost and Dirk Kraaijpoel for their comments on the geological zonation model. This paper benefitted from the comments of an anonymous reviewer.

Open Access This article is distributed under the terms of the Creative Commons Attribution 4.0 International License (http://creativecommons.org/licenses/by/4.0/), which permits unrestricted use, distribution, and reproduction in any medium, provided you give appropriate credit to the original author(s) and the source, provide a link to the Creative Commons license, and indicate if changes were made.

\section{References}

Bazzurro P, Cornell CA (2004a) Ground-motion amplification in nonlinear soil sites with uncertain properties. Bull Seismol Soc Am 94:2090-2109

Bazzurro P, Cornell CA (2004b) Nonlinear soil-site effects in probabilistic seismic hazard analysis. Bull Seismol Soc Am 94(6):2110-2123

Bommer JJ, Stafford PJ, Edwards B, Dost B, van Dedem E, Rodriguez-Marek A, Kruiver PP, van Elk J, Doornhof D (2017) Framework for a ground-motion model for induced seismic hazard and risk analysis in the Groningen gas field, the Netherlands. Earthq Spectr 33(2). doi:10.1193/ 082916EQS138M

Bourne SJ, Oates SJ, Bommer JJ, Dost B, van Elk J, Doornhof D (2015) A Monte Carlo method for probabilistic hazard assessment of induced seismicity due to conventional natural gas production. Bull Seismol Soc Am 105:1721-1738

Chilès J-P, Delfiner P (2012) Geostatistics_modeling spatial uncertainty. Wiley, Hoboken, p 699

Coppersmith KJ, Bommer JJ, Hanson KL, Unruh J, Coppersmith RT, Wolf L, Youngs R, Rodriguez-Marek A, Al Atik L, Toro G (2014) Hanford sitewide probabilistic seismic hazard analysis. PNNL-23361 Pacific Northwest National Laboratory, Richland Washington http://www.hanford.gov/page.cfm/ OfficialDocuments/HSPSHA

Darendeli M (2001) Development of a new family of normalized modulus reduction and material damping curves. Dissertation, Department of Civil Engineering, University of Texas, Austin, TX 
de Mulder EFJ, Geluk MC, Ritsema I, Westerhoff WE, Wong TE (2003) De ondergrond van Nederland. Wolters-Noordhoff

Electrical Power Research Instititue, EPRI (2013) Seismic evaluation guidance. Screening, prioritization and implementation details (SPID) for the Resolution of Fukushima Near-Term Task Force Recommendation 2.1: Seismic. Report no. 1025281. February

Ernst F (2013) Modal elastic inversion. In: 75th EAGE Conference \& exhibition incorporating SPE EUROPEC 2013, London, 2013. doi:10.3997/2214-4609.20130001

Goovaerts P (1997) Geostatistics for natural resources evaluation. Oxford University Press, New York, p 483

Guéguen P, Cornou C, Garambois S, Banton J (2007) On the limitation of the H/V spectral ratio using seismic noise as an exploration tool: application to the Grenoble valley (France), a small apex ratio basin. Pure Appl Geophys 164(1):115-134

Gunnink JL, Maljers D, Van Gessel SF, Menkovic A, Hummelman HJ (2013) Digital Geological Model (DGM): a 3D raster model of the subsurface of the Netherlands. Neth J Geosci 92:33-46

Hardin BO (1978) The nature of stress-strain behavior for soils. In: ASCE Geotechnical Engineering Division Specialty Conference, Pasadena, California, June 19-21, 1978

Havenith HB, Fäh D, Polom U, Roullé A (2007) S-wave velocity measurements applied to the seismic microzonation of Basel, Upper Rhine Graben. Geophys J Int 170(1):346-358

Jamiolkowski M, Leroueil S, Lo Presti D (1991) Theme lecture: design parameters from theory to practice. In: Proceedings, Geo-Coast, vol 2. Pp 877-917

Kruiver PP, de Lange G, Wiersma A, Meijers P, Korff M, Peeters J, Stafleu J, Harting R, Dambrink R, Busschers F, Gunnink JL (2015) Geological schematisation of the shallow subsurface of Groningenfor site response to earthquakes for the Groningen gas field. Deltares report no. 1209862-005-GEO0004-v5-r. http://kennisonline.deltares.nl/product/30895

Menq F (2003) Dynamic properties of sandy and gravelly soils. Dissertation, University of Texas

Montgomery DC, Runger GC, Hubele NF (2011) Engineering statistics. Wiley

Park CB, Miller RD, Xia J (1999) Multichannel analysis of surface waves (MASW). Geophysics 64:800-808

Pitilakis K, Raptakis D, Lontzetidis K, Tika-Vassilikou T, Jongmans D (1999) Geotechnical and geophysical description of EURO-SEISTEST, using field, laboratory tests and moderate strong motion recordings. J Earthq Eng 3(3):381-409. doi:10.1080/13632469909350352

Robertson PK (1990) Soil classification using the cone penetration test. Can Geotech J 27(1):151-158

Rodriguez-Marek A, Kruiver PP, Meijers P, Bommer JJ, Dost B, van Elk J, Doornhof D (2017) A regional site response model for the Groningen gas field. Re-submitted to Bulletin of the Seismological Society of America following revision

Soares A (1992) Geostatistical estimation of multi-phase structure. Math Geol 24(2):149-160

Stafleu J, Dubelaar CW (2016) Product specification subsurface model GeoTOP, version 1.3. TNO report R10133, 53 pp. https://www.dinoloket.nl/en/subsurface-models

Stafleu J, Maljers D, Gunnink JL, Menkovic A, Busschers FS (2011) 3D modelling of the shallow subsurface of Zeeland, the Netherlands. Neth J Geosci 90:293-310

Sykora DW (1987) Examination of existing shear wave velocity and shear modulus correlations in soils. Corps of Engineers, Vicksburg

Toro GR (1995) Probabilistic models of site velocity profiles for generic and site-specific ground-motion amplification studies. Upton, New York

Vernes RW, van Doorn THM (2005) Van Gidslaag naar Hydrogeologische Eenheid-Toelichting op de totstandkoming van de dataset REGIS II. TNO report report 05-038-B, $105 \mathrm{pp}$

Vos PC (2015) Origin of the Dutch coastal landscape. Long-term landscape evolution of the Netherlands during the Holocene, described and visualized in national, regional and local palaeogeographical map series. Dissertation, Utrecht University

Vos PC, Knol E (2015) Holocene landscape reconstruction of the Wadden Sea area between Marsdiep and Weser. Neth J Geosci 94:157-183

Vos PC, Bazelmans J, Weerts HJT, van der Meulen MJ (2011) Atlas van Nederland in het Holoceen: landschap en bewoning vanaf de laatste ijstijd tot nu. Bert Bakker, Amsterdam

Wassing BBT, Maljers D, Westerhoff RS, Bosch JHA, Weerts HJT (2003) Seismisch hazard van geïnduceerde aardbevingen, Rapportage fase 1. TNO Geological Survey of the Netherlands Report number NITG-03-185-C-def (in Dutch)

Yamada S, Hyodo M, Orense RP, Dinesh S (2008) Initial shear modulus of remolded sand-clay mixtures. J Geotech Geoenviron Eng 134:960-971

Yilmaz Ö (2001) Seismic data analysis. Investigations in Geophysics. Society of Exploration Geophysicists, Tulsa. doi:10.1190/1.9781560801580 